\title{
Determining Effects of Wagon Mass and Vehicle Velocity on Vertical Vibrations of a Rail Vehicle Moving with a Constant Acceleration on a Bridge Using Experimental and Numerical Methods
}

\author{
C. Mrzrak and İ. Esen \\ Department of Mechanical Engineering, Karabük University, 78050 Karabük, Turkey \\ Correspondence should be addressed to C. Mizrak; cihanmizrak@karabuk.edu.tr
}

Received 26 February 2015; Revised 29 April 2015; Accepted 2 May 2015

Academic Editor: Haifeng Gao

Copyright (c) 2015 C. Mizrak and İ. Esen. This is an open access article distributed under the Creative Commons Attribution License, which permits unrestricted use, distribution, and reproduction in any medium, provided the original work is properly cited.

\begin{abstract}
Vibrations are vital for derailment safety and passenger comfort which may occur on rail vehicles due to the truck and nearby conditions. In particular, while traversing a bridge, dynamic interaction forces due to moving loads increase the vibrations even further. In this study, the vertical vibrations of a rail vehicle at the midpoint of a bridge, where the amount of deflection is expected to be maximum, were determined by means of a 1:5 scaled roller rig and Newmark- $\beta$ numerical method. Simulations for different wagon masses and vehicle velocities were performed using both techniques. The results obtained from the numerical and experimental methods were compared and it was demonstrated that the former was accurate with an $8.9 \%$ error margin. Numerical simulations were performed by identifying different test combinations with Taguchi experiment design. After evaluating the obtained results by means of an ANOVA analysis, it was determined that the wagon mass had a decreasing effect on the vertical vibrations of the rail vehicle by $2.087 \%$, while rail vehicle velocity had an increasing effect on the vibrations by $96.384 \%$.
\end{abstract}

\section{Introduction}

Design and production of high-speed trains require a thorough understanding of the dynamic behaviour of these vehicles moving on ground and flexible structure. In order to determine the vibrations occurring on rail vehicles on flexible structure under different loading conditions, a number of numerical and experimental studies have been presented in literature. A review of previous studies in the literature indicated that the utilized mathematical models to assess bridge-vehicle interaction have been developed using either the Euler-Bernoulli theory [1-6] or the Timoshenko beam theory $[5,7,8]$. Rail vehicles have been modelled as having two wheel sets [9-11] and two-stage suspensions $[10,12]$ and both with each axis being defined as a sprung mass. The contact points between the rail vehicle and the bridge have been modelled based on the assumption that the wheel sets are moving loads $[3,7]$ or moving masses $[1,3,5]$. The vehiclebridge interactions have been modelled either by using the mode superposition method, where the bridge, vehicle, and rail irregularities interact with one another $[4,12]$, or by using the discrete finite element method $[2,9,13]$. The interactions between the modelled rail vehicle and the bridge have been numerically determined using the Newton-Raphson and Newmark methods [11]. The effect of velocity, load, and damping on the vehicle and bridge has been investigated by using a three-dimensional train and a finite element model of the bridge [14]. Since the most commonly encountered rail irregularities have been undulations, wearing, and railroad deteriorations due to certain ground movements, some researchers have investigated the effects of the rail defects on the dynamic behaviour of the vehicle and the bridge $[6,15,16]$. The deteriorating effects of the rails and the railroad have been used as inputs in the system as random and nonrandom 
impacts [6]. Determination of driving comfort in high-speed trains passing over a bridge has been performed [17]. To this end, the rail vehicle, rail, rail pad, sleeper, ballast, and the bridge have been modelled interactively. The effects of velocity, rail irregularities, and the primary and secondary suspension systems on driving comfort have been examined separately, and it has been determined that the effect of rail irregularity has been more significant than the effects of the other parameters. In another study, the theoretical and applied interaction between the high-speed train and the bridge have been compared to each other [18]. Besides, the acceleration values of the bogie were measured by means of sensors, and the acceleration values of the rail vehicle have been estimated using the Principle Component Analysis (PCA) and Partial Least Square (PLS) techniques [19].

Since safety of the rail transport with increasing transportation speeds is of importance in terms of derailment and passenger comfort, some more precise studies have to be performed. However, considering realistic test conditions, a fully realistic experimental study cannot be performed since the rail vehicles and other units of railway systems may be costly. From this point of view, some economic small scale test equipment and numerical models have been generally used to estimate the dynamic behaviour of the rail vehicle within the desired scenarios. The first small scale roller rig $[18,20]$ has been produced in order to determine the wheelrail interaction. In the Chesapeake and Ohio Baltimore and Ohio railways, bogie designs for the double modal load wagon were tested in a $1: 10$ roller rig. In Japan, $1: 5$ and $1: 10$ scaled roller rigs have been used [4] to test the oscillation features of the high speed vehicles. The 1:5 scaled roller rigs have been constructed by Princeton University in USA [21] and have been used to investigate contact forces between wheel and flange and overturning modes of the rail vehicle. On the other hand, theoretical models developed for vehicle instability have been tested using 1:5 scaled roller rigs at Manchester Metropolitan University in England [22, 23]. The first small scale roller rig in Germany [24] has been developed by RWTH Aachen Technical University. A 1:5 scaled roller rig has been developed in the German Aerospace Center [22] on the basis of the ratio theory. At the National Institute for Transport and Security Research in France, a 1: 4 scaled roller rig has been formed [25], and the rail vehicle suspension system has been designed. On the other hand, the $1: 4$ and $1: 5$ scaled roller rigs developed by the Politecnico University [26] has been used to investigate the stability conditions, contact forces, and adhesion of rail vehicles [27, 28].

The studies of the accelerating motion of a rail vehicle on flexible structures as a bridge are limited and this phenomenon has not been fully studied yet. In addition, experimental studies on rail vehicle-bridge interaction using $1: 5$ scaled roller rig have not been studied yet. In this study, experimental and numerical methods have been applied in order to determine the influences of vehicle velocity and wagon mass for the following specific case: vehicle moves at constant acceleration on a bridge and vehicle is at the midpoint of the bridge. Experimental studies are carried out using a 1:5 scaled roller rig. The interaction of the rail vehicle and the bridge is modelled using mode superposition of the bridge and its coupled equation of motion with an accelerating vehicle. Then the coupled equation of the motion of the whole system is solved using the Newmark- $\beta$ method. Then, the experimentally and numerically obtained results are compared and the accuracy of the mathematical model is tested. Numerical simulations are achieved by determining different test combinations using the Taguchi design of experiment (DOE). The obtained results are assessed using ANOVA analysis; then, effects of the wagon mass and the vehicle velocity on the vertical vibrations of a rail vehicle crossing over the midpoint of the bridge.

\section{Bogie-Bridge Interaction Model}

2.1. Bogie Model. Rail vehicles could be modelled using different degrees of freedom [2, 6, 9]. Figure 1(a) shows a quarter-vehicle model passing over a bridge with a length of $L$ with constant acceleration.

The bogie model shown in Figure 1(b) is modelled with 5 degrees of freedom of the vertical displacement of the rail vehicle $Z_{v}$, the vertical displacement of the bogie frame $Z_{b j}$, the angular displacement due to pitch motion of the bogie frame $\theta$, and the vertical displacements of front and back wheels of the bogie, $Z_{t 1}$ and $Z_{t 2}$, respectively.

Therefore, the equation of the vertical motion for the wagon,

$$
m_{v} \ddot{z}_{v}+c_{2} \dot{z}_{v}-c_{2} \dot{z}_{b j}+k_{2} z_{v}-k_{2} z_{b j}=0
$$

the definition for the vertical motion for the bogie frame,

$$
\begin{gathered}
m_{b j} \ddot{z}_{b j}-c_{2} \dot{z}_{v}+\left(c_{2}+c_{11}+c_{12}\right) \dot{z}_{b j}+\left(c_{11} l_{a}-c_{12} l_{b}\right) \dot{\theta} \\
-c_{11} \dot{z}_{t 1}-c_{12} \dot{z}_{t 2}-k_{2} z_{v}+\left(k_{2}+k_{11}+k_{12}\right) z_{b j} \\
+\left(k_{11} l_{a}-k_{12} l_{b}\right) \theta-k_{11} z_{t 1}-k_{12} z_{t 2}=0,
\end{gathered}
$$

the definition for the pitch motion for the bogie frame,

$$
\begin{aligned}
J_{b j} \ddot{\theta}+ & \left(c_{11} l_{a}-c_{12} l_{b}\right) \dot{z}_{b j}+\left(c_{11} l_{a}^{2}+c_{12} l_{b}^{2}\right) \dot{\theta}-c_{11} l_{a} \dot{z}_{t 1} \\
& +c_{12} l_{b} \dot{z}_{t 2}+\left(k_{11} l_{a}-k_{12} l_{b}\right) z_{b j}+\left(k_{11} l_{a}^{2}+k_{12} l_{b}^{2}\right) \theta \\
& -k_{11} l_{a} z_{t 1}+k_{12} l_{b} z_{t 2}=0,
\end{aligned}
$$

and the definition for the vertical motion for the wheel sets,

$$
\begin{gathered}
m_{t 1} \ddot{z}_{t 1}-c_{11} \dot{z}_{b j}-c_{11} l_{a} \dot{\theta}+\left(c_{11}+c_{t 1}\right) \dot{z}_{t 1}-c_{t 1} \dot{z}_{c t 1} \\
-k_{11} z_{b j}-k_{11} l_{a} \theta+\left(k_{11}+k_{t 1}\right) z_{t 1}-k_{t 1} z_{c t 1}=0, \\
m_{t 2} \ddot{z}_{t 2}-c_{12} \dot{z}_{b j}+c_{12} l_{b} \dot{\theta}+\left(c_{12}+c_{t 2}\right) \dot{z}_{t 2}-c_{t 2} \dot{z}_{c t 2} \\
-k_{12} z_{b j}+k_{12} l_{b} \theta+\left(k_{12}+k_{t 2}\right) z_{t 2}-k_{t 2} z_{c t 2}=0,
\end{gathered}
$$

are obtained as above. Here, $m_{v}$ is the mass of the half wagon; $m_{b j}$ is the bogie mass; $J_{b j}$ is the moment of inertia of the bogie; $m_{t 1}$ and $m_{t 2}$ are the wheel masses; $l_{a}$ is the distance between the front wheel axis and the center of bogie; $l_{b}$ is the distance between the rear wheel axis and the center 


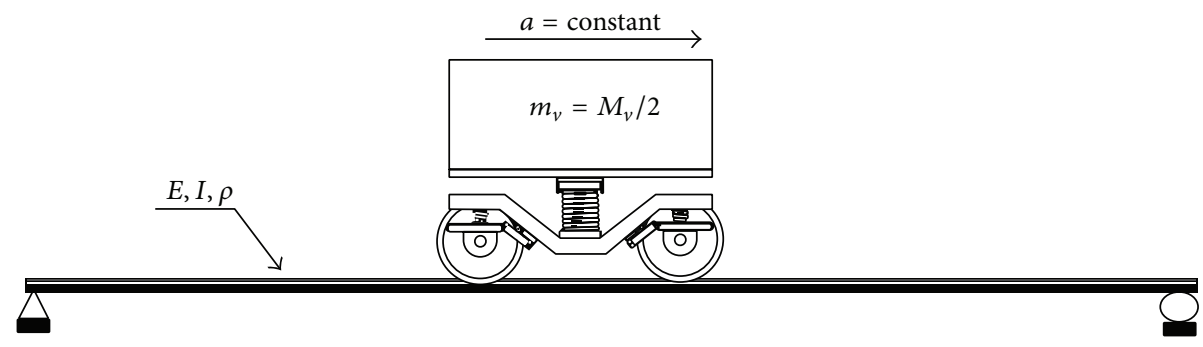

(a)

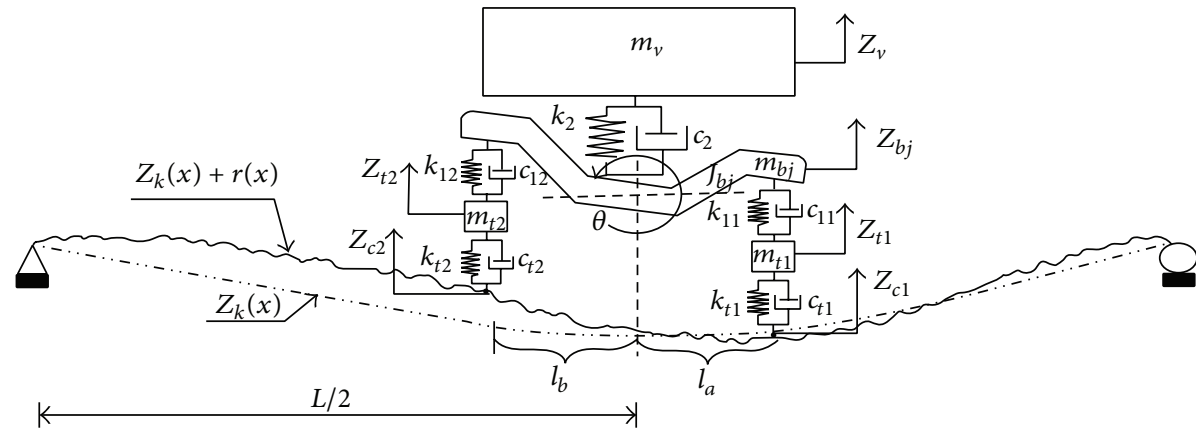

(b)

Figure 1: (a) Bogie moving on a railway bridge with constant acceleration; (b) bogie-bridge model with 5 degrees of freedom.

of bogie; $k_{11}, c_{11}, k_{12}, c_{12}$ are the front and back suspension parameters of the bogie primary suspension system, respectively; $k_{t 1}, c_{t 1}, k_{t 2}, c_{t 2}$ are the parameters for Hertzian contact occurring between the front and back wheels and the rail, respectively; $k_{2}, c_{2}$ are the secondary suspension parameters; $Z_{c t 1}$ and $Z_{c t 1}$ are the displacements of the front and back wheels at the contact points, respectively; $\dot{Z}_{c t 1}$ and $\dot{Z}_{c t 2}$ are the displacement rates of the contact points for the front and back wheels, respectively. From (1)-(4), the general equation of the motion for the quarter vehicle is obtained as follows:

$$
\left[M_{s v}\right]\left\{\ddot{Z}_{s v}\right\}+\left[C_{s v}\right]\left\{\dot{Z}_{s v}\right\}+\left[K_{s v}\right]\left\{Z_{s v}\right\}=\left\{Q_{s v}\right\}
$$

Matrixes of general mass $\left(M_{s v}\right)$, general damping $\left(C_{s v}\right)$, and general stiffness $\left(K_{s v}\right)$ and vectors of general displacement $\left(K_{s v}\right)$ and general force $\left(Q_{s v}\right)$ for the quarter vehicle are calculated based on (5) (Appendix A).

2.2. Bridge Model. As the ratio of the bridge length to the cross section is relatively small, the uniform simply supported Euler-Bernoulli beam model and the mode superposition method are selected $[2,29]$ :

$$
\begin{gathered}
E I \frac{\partial^{4} z_{k}(x, t)}{\partial x^{4}}+\rho \frac{\partial^{2} z_{k}(x, t)}{\partial t^{2}}+\mu \frac{\partial z_{k}(x, t)}{\partial t} \\
=-F(x, t) \delta\left(x-\frac{a t^{2}}{2}\right) .
\end{gathered}
$$

In (6), EI is the flexural rigidity of the beam, $E$ is Young's modulus of the beam, $I$ is the moment of inertia of the cross section of the beam, $\rho$ is the mass of the beam per unit length, $\mu$ is the damping coefficient per unit length, $F(x, t)$ is the coupled force on the beam, $Z_{k}$ is the beam's displacement on the contact point $t$ of the vehicle on the bridge, and $\delta$ is the function of Dirac [3].

The forces caused by the vehicle on the bridge during its pass over the bridge based on the position of the front and rear wheels are

$$
\int_{m^{1}}^{m^{2}} f(x) \delta(x-t) d x= \begin{cases}0, & t<m^{1} \\ f(t), & \left(m^{1} \leq t \leq m^{2}\right) \\ 0, & t>m^{2}\end{cases}
$$

where $m^{1}$ stands for the time at which the front wheel enters the bridge and $\mathrm{m}^{2}$ stands for the time at which the back wheel leaves the bridge. According to the Galerkin method, the vertical displacement in the bridge can be found as [2]

$$
z_{k}(x, t)=\sum_{i=1}^{N} \tilde{\phi}_{i}(x) \eta_{i}(t)
$$

where $\widetilde{\phi}_{i}(x)$ are the transverse Eigen functions (i.e., modal shapes) of the beam and $\eta_{i}(t)$ are the generalized coordinates for the elastic deflection of the beam element. Normalized Eigen functions of a simply supported beam are given below [2]:

$$
\tilde{\phi}_{i}(x)=A \sin \frac{i \pi x}{L} .
$$

The modal equation of the bridge is

$$
\ddot{\eta}_{n}+2 \zeta_{n} \omega_{n} \dot{\eta}_{n}+\omega_{n}^{2} \eta_{n}=-F_{1}(t) \phi_{1 n} \delta_{1}-F_{2}(t) \phi_{2 n} \delta_{2} .
$$


In (10), $\zeta_{n}$ and $\omega_{n}$ are the modal damping and the modal natural frequency matrixes, respectively. The sizes of these matrixes are defined by modal coordinate vector $\eta_{n}$, expressing the mode of vibration of the bridge. The modal equations are composed of independent equations with single degree of freedom, each of which expresses one vibration mode of the bridge. In order to solve this equation, piecewise interpolation techniques such as the Newmark and the Runge-Kutta methods are used. The characteristic equations describing the effects of the front wheel (11) and the back wheel (12) on the bridge are as follows:

$$
\begin{aligned}
& \phi_{1 n}=\phi_{n}\left(\frac{a t^{2}}{2}\right)=\sqrt{\frac{2}{\rho L}} \sin \frac{n \pi a t^{2}}{2 L}, \\
& \phi_{2 n}=\phi_{n}\left(\frac{a t^{2}}{2}-l\right)=\sqrt{\frac{2}{\rho L}} \sin \frac{n \pi\left(a t^{2}-2 l\right)}{2 L} .
\end{aligned}
$$

The Dirac functions for the front wheel (13) and the back wheel (14) are given as follows:

$$
\begin{aligned}
& \delta_{1}(t)= \begin{cases}1, & 0 \leq t \leq \frac{l}{a t}, \\
0, & \text { else, }\end{cases} \\
& \delta_{2}(t)= \begin{cases}1, & \frac{l}{a t} \leq t \leq \frac{l+L}{a t}, \\
0, & \text { else. }\end{cases}
\end{aligned}
$$

In this context, the vertical displacements that the front and back wheels cause at contact points on the rail $Z_{k}$ are calculated using the vertical displacement of the bridge $r$ and the rail irregularities. The total displacement values that the front and the back wheels cause at the contact points on the bridge can be determined using (15), while the change of these points in time can be obtained by using (16). Consider

$$
\begin{aligned}
& \left.z_{c t 1}\right|_{x_{1}=a t^{2} / 2}=\left.z_{k}\left(x_{1}, t\right)\right|_{x_{1}=a t^{2} / 2}+\left.r\left(x_{1}, t\right)\right|_{x_{1}=a t^{2} / 2} \\
& =z_{k}\left(\frac{a t^{2}}{2}, t\right)+r\left(\frac{a t^{2}}{2}\right) \\
& =\sum_{i=1}^{N} \varphi_{i}\left(\frac{a t^{2}}{2}\right) \eta_{i}(t)+r_{1}, \\
& \left.z_{c t 2}\right|_{x_{2}=a t^{2} / 2-l} \\
& =\left.z_{k}\left(x_{2}, t\right)\right|_{x_{2}=a t^{2} / 2-l}+\left.r\left(x_{2}, t\right)\right|_{x_{2}=a t^{2} / 2-l} \\
& =z_{k}\left(\frac{a t^{2}}{2}-L, t\right)+r\left(\frac{a t^{2}}{2}\right) \\
& =\sum_{i=1}^{N} \varphi_{i}\left(\frac{a t^{2}}{2}-L\right) \eta_{i}(t)+r_{2},
\end{aligned}
$$

$$
\begin{aligned}
\left.\dot{z}_{c t 1}\right|_{x_{1}=a t^{2} / 2} & {\left[\sum_{i=1}^{N} \dot{\phi}_{i}\left(\frac{a t^{2}}{2}\right) \eta_{i}(t)+\phi_{i}\left(\frac{a t^{2}}{2}\right) \dot{\eta}_{i}(t)\right] } \\
& +\dot{r}\left(\frac{a t^{2}}{2}\right), \\
\left.\dot{z}_{c t 2}\right|_{x_{2}=a t^{2} / 2-l} & {\left[\sum_{i=1}^{N} \dot{\phi}_{i}\left(\frac{a t^{2}}{2}-l\right) \eta_{i}(t)+\dot{\phi}_{i}\left(\frac{a t^{2}}{2}-l\right) \dot{\eta}_{i}(t)\right] } \\
& +\dot{r}\left(\frac{a t^{2}}{2}-l\right) .
\end{aligned}
$$

The resulting static loading at contact points is calculated using the mass of the half wagon $m_{v}$, mass of the bogie $m_{b j}$, and the mass of the wheel sets $\left(m_{t 1}, m_{t 2}\right)$ :

$$
\begin{aligned}
& W_{1}=\left(\left(m_{v}+m_{b j}\right) \frac{l_{b}}{L}+m_{t 1}\right) g, \\
& W_{2}=\left(\left(m_{v}+m_{b j}\right) \frac{l_{a}}{L}+m_{t 2}\right) g .
\end{aligned}
$$

Total force at the contact points on the bridge can be calculated using the following equations:

$$
\begin{aligned}
& F_{1}\left(x_{1}, t\right)=W_{1}-k_{t 1}\left(z_{t 1}-z_{c t 1}\right)-c_{t 1}\left(\dot{z}_{t 1}-\dot{z}_{t 1}\right), \\
& F_{2}\left(x_{2}, t\right)=W_{2}-k_{t 2}\left(z_{t 2}-z_{c t 2}\right)-c_{t 2}\left(\dot{z}_{t 2}-\dot{z}_{c 2}\right) .
\end{aligned}
$$

The general couple equation of the bogie and the bridge can be obtained as follows:

$$
\left[M_{c}\right]\left\{\ddot{Z}_{c}\right\}+\left[C_{c}\right]\left\{\dot{Z}_{c}\right\}+\left[K_{c}\right]\left\{Z_{c}\right\}=\left\{Q_{c}\right\} .
$$

The general mass $M_{c}$, general damping $C_{c}$, general stiffness matrixes $K_{c}$, general force vector $Q_{c}$, and the general displacement vector $Z_{c}$ of the vehicle-bridge interaction are all provided in Appendix B.

2.3. Newmark- $\beta$ Methodology. The Newmark- $\beta$ method is one of the numeric integration methods that calculate the dynamic nature of the vehicle-bridge interaction at very short time and condition intervals. To perform such calculations, it is assumed that the structure has certain rigidity and damping characteristics for each of these intervals and that the external effects are known. The following points represent the content of the Newmark- $\beta$ algorithm [20]:

(i) In the initial stage $(t=0)$, the displacement $Z_{c}$, velocity $\dot{Z}_{c}$, and acceleration $\ddot{Z}_{c}$ should be known.

(ii) The time intervals and Newmark- $\beta$ constants should be determined:

$$
\begin{aligned}
\beta & \geq 0.5, \\
\alpha & \geq 0.25(0.5+\beta)^{2}, \\
a_{0} & =\frac{1}{\alpha \Delta t^{2}},
\end{aligned}
$$




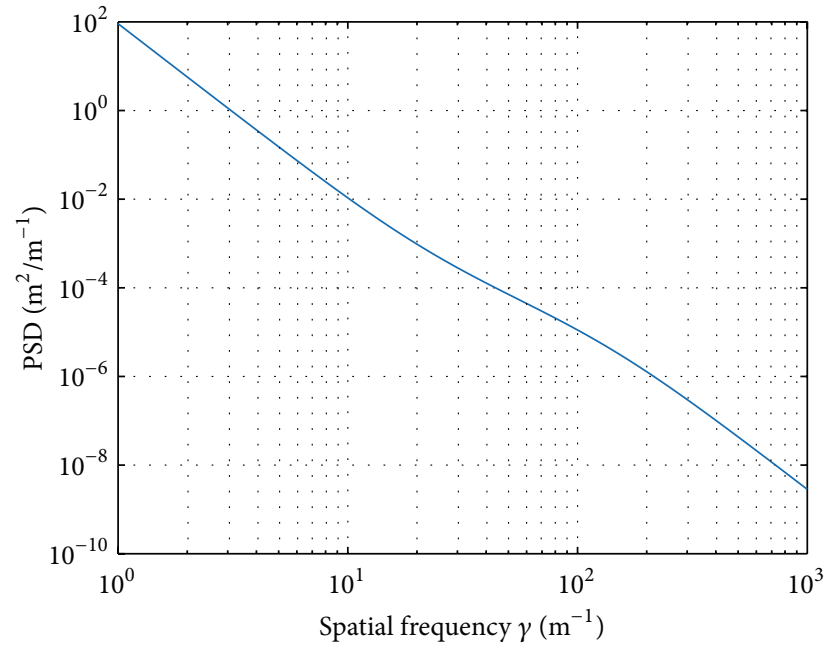

(a)

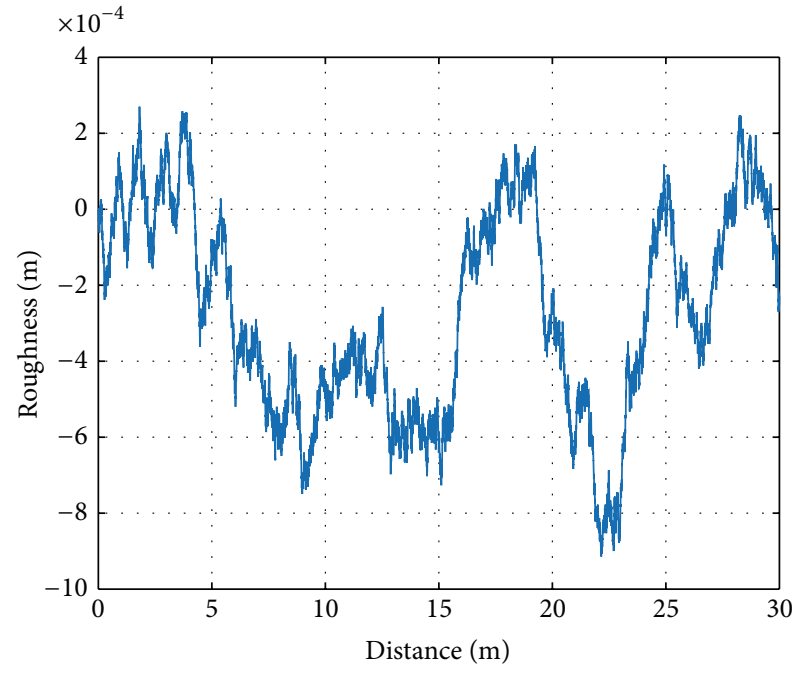

(b)

FIgURE 2: Rail irregularity with respect to (a) PSD and (b) distance.

$$
\begin{aligned}
& a_{1}=\frac{\beta}{\alpha \Delta t}, \\
& a_{2}=\frac{1}{\alpha \Delta t}, \\
& a_{3}=\frac{1}{2 \alpha}-1, \\
& a_{4}=\frac{\beta}{\alpha}-1, \\
& a_{5}=\frac{\Delta t}{2}\left(\frac{\beta}{\alpha}-2\right), \\
& a_{6}=\Delta t(1-\beta), \\
& a_{7}=\Delta t \beta .
\end{aligned}
$$

(iii) The effective stiffness matrix is

$$
\left[\widetilde{K}_{c}\right]=\left[K_{c}\right]+a_{0}\left[M_{c}\right]+a_{1}\left[C_{c}\right] .
$$

(iv) The effective force at $\widetilde{t}=t+\Delta t$ is

$$
\begin{aligned}
{ }^{\tilde{}}\left\{\widetilde{Q}_{c}\right\}= & { }^{\tilde{}}\left\{\widetilde{Q}_{c}\right\}+\left[M_{c}\right]\left(a_{0}^{t}\left\{Z_{c}\right\}+a_{2}^{t}\left\{\dot{Z}_{c}\right\}+a_{3}^{t}\left\{\ddot{Z}_{c}\right\}\right) \\
& +\left[C_{c}\right]\left(a_{1}^{t}\left\{Z_{c}\right\}+a_{4}^{t}\left\{\dot{Z}_{c}\right\}+a_{5}^{t}\left\{\ddot{Z}_{c}\right\}\right) .
\end{aligned}
$$

(v) The displacement at $\widetilde{t}=t+\Delta t$ is

$$
\left[\widetilde{K}_{c}\right]^{\tilde{t}}\left\{Z_{c}\right\}={ }^{\widetilde{t}}\left\{\widetilde{Q}_{c}\right\} .
$$

(vi) The general acceleration vector (24) and the general velocity vector (25) at $\tilde{t}=t+\Delta t$ are obtained from the general displacement vector:

$$
\begin{aligned}
& { }^{\tilde{t}}\left\{\ddot{Z}_{c}\right\}=a_{0}^{t}\left({ }^{\tilde{t}}\left\{Z_{c}\right\}-{ }^{t}\left\{Z_{c}\right\}\right)-a_{2}^{t}\left\{\dot{Z}_{c}\right\}-a_{3}^{t}\left\{\ddot{Z}_{c}\right\}, \\
& { }^{\tilde{t}}\left\{\dot{Z}_{c}\right\}={ }^{t}\left\{\dot{Z}_{c}\right\}+a_{6}^{t}\left\{\ddot{Z}_{c}\right\}+a_{7}^{\tilde{t}}\left\{\ddot{Z}_{c}\right\} .
\end{aligned}
$$

The equation developed by taking the root mean squares (RMS) of the rail vehicle accelerations [31] is

$$
a^{\mathrm{wrms}}=\left[\frac{1}{T} \int_{0}^{T}\left[\ddot{z}_{v}^{w}(t)\right]^{2} d t\right]^{0.5} .
$$

2.4. Rail Irregularities. Over time, wearing, undulation, and ground movements cause certain irregularities on the rails. These random rail irregularities are expressed as a Power Spectral Density using a spatial frequency term, $\varphi$ [32]:

$$
\widetilde{S}_{Z Z}(f)=\frac{S_{Z Z}(\varphi)}{v_{0}}
$$

where $v_{0}$ stands for the vehicle velocity. According to the Federal Railway Administration (FRA), the rail irregularities in the vertical direction are defined as 6 classes. The Power Spectral Density (PSD) function of the rail irregularities is given in [33]

$$
S_{Z Z}(\varphi)=\frac{A \varphi_{2}^{2}\left(\varphi^{2}+\varphi_{1}^{2}\right)}{\varphi^{4}\left(\varphi^{2}+\varphi_{2}^{2}\right)},
$$

where $A$ is the rail irregularity constant $(0.1675)$, while $\varphi_{1}$ and $\varphi_{2}$ are the two cutoff spatial frequency values which are (23.294) and (13.123), respectively. Wavelength values of the frequency vary between (1.5) and (300) $\mathrm{m}$ [33]. In order to obtain rail irregularities in time domain for the indicated PSD (Power Spectral Density) function, Fourier transformations are used:

$$
h(x)=\sum_{k} \sqrt{2 \Delta \varphi S_{Z Z}(k \Delta \varphi)} \operatorname{Cos}\left(k \Delta \varphi x+\psi_{k}\right),
$$

where $\psi_{k}$ stands for random numbers in the interval $(-\pi, \pi)$. Figure 2 shows the rail irregularity with respect to (a) PSD and (b) distance. 


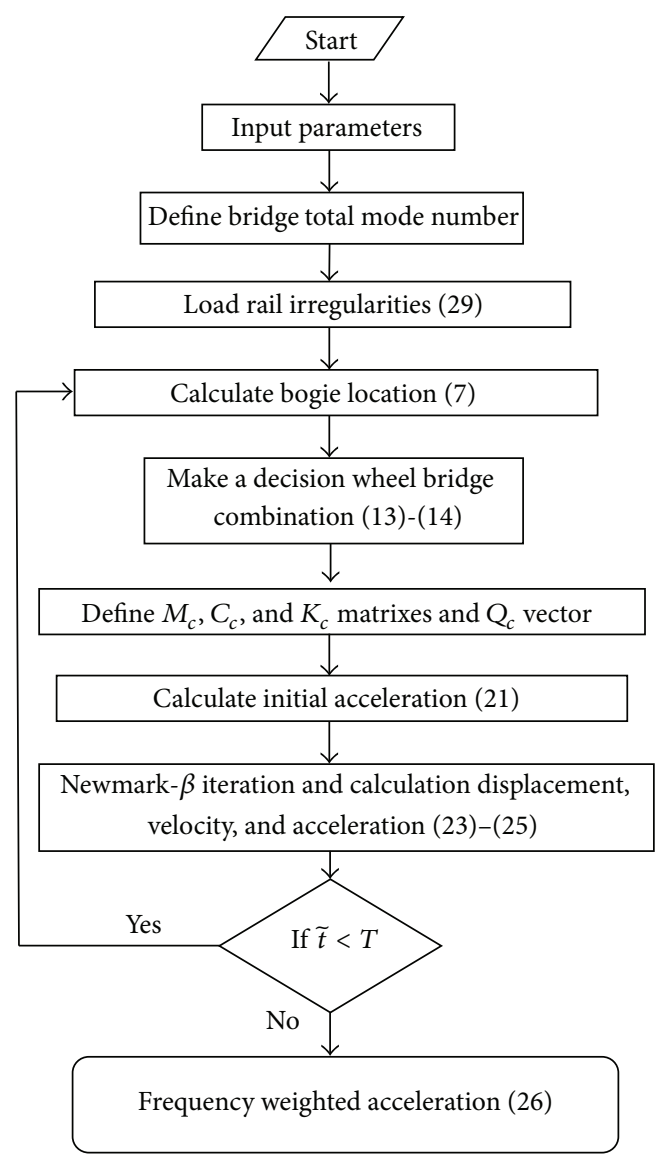

FIGURE 3: Flowchart of the numerical method.

In the flow diagram obtained from the numerical model (Figure 3), the mathematical models of the rail vehicle (5) and of the bridge (10) are coupled by means of mode superposition method (19). The location of the rail vehicle axes on the bridge is determined at each iteration and the general mass, damping, and the stiffness matrixes of the system are formed (Appendix B). With the Newmark- $\beta$ numerical method, the initial acceleration values are calculated for each iteration and the location, velocity, and the acceleration of the wagon are obtained.

\section{1 : 5 Scaled Roller Rigs}

While forming a small scaled model of a rail vehicle, first of all, the scale should be determined to design the unit. The previous studies show that the scale has been generally selected as 4 or 5 based on considerations of dimensions, structure, and cost. Among these, there are four different approaches for 1:5 scaled rail vehicle on the basis of length [30]. A comparison of four scale factors based on the rail vehicle parameters is given in Table 1.

The study in [30] has shown that the closest results to $1: 1$ scaled real model have been obtained from the Pascal scale factor (Table 1). Therefore, the Pascal scale factor is employed in this study. The design parameters for the 1:5
TABLE 1: Comparing of 1:5 scaled roller rig approaches [30].

\begin{tabular}{lcccc}
\hline Scaling factors & Jaschinski & Pascal & Iwnicki & Jaschinski modified \\
\hline$\varphi_{l}$ length & 5 & 5 & 5 & 5 \\
$\varphi_{t}$ time & $\sqrt{ } 5$ & 5 & 1 & $\sqrt{ } 5$ \\
$\varphi_{v}$ velocity & $\sqrt{ } 5$ & 1 & 5 & $\sqrt{ } 5$ \\
$\varphi_{a}$ acceleration & 1 & $1 / 5$ & 5 & 1 \\
$\varphi_{m}$ mass & 125 & 125 & 125 & 75 \\
$\varphi_{F}$ force & 125 & 25 & 625 & 75 \\
$\varphi_{\rho}$ density & 1 & 1 & 1 & 0.6 \\
$\varphi_{E}$ elastic module & 1 & 1 & 1 & 3 \\
$\varphi_{w}$ weight & 125 & 125 & 125 & 75 \\
$\varphi_{K}$ stiffness & 25 & 5 & 125 & 15 \\
$\varphi_{T}$ creep force & 125 & 25 & 625 & 75 \\
$\varphi_{C}$ damper & $25 \sqrt{ } 5$ & 25 & 125 & $25 \sqrt{ } 5$ \\
$\varphi_{C t}$ torsion damper & 625 & 125 & 3125 & 375 \\
$\varphi_{K t}$ torsion stiffness & $625 \sqrt{ } 5$ & 625 & 3125 & $625 \sqrt{ } 5$ \\
$\varphi_{I}$ inertia & 3125 & 3125 & 3125 & 1875 \\
$\varphi_{\mu}$ friction & 1 & 1 & 1 & 1 \\
\hline
\end{tabular}

TABLE 2: Bogie and bridge parameters for 1:5 scaled roller rig.

\begin{tabular}{lc}
\hline Parameters & Values \\
\hline$E I:$ stiffness of bridge $(\mathrm{MN} / \mathrm{m})$ & 319.2 \\
$m_{v}:$ mass of the wagon $(\mathrm{kg})$ & 166,199 \\
$m_{b j}:$ mass of the bogie frame $(\mathrm{kg})$ & 24 \\
$l_{b}+l_{a}:$ distance between two centers of axles $(\mathrm{m})$ & 0.6 \\
$J:$ moment of inertia of the bogie frame $\left(\mathrm{tm}^{2}\right)$ & 0.00128 \\
$m_{t 1}, m_{t 2}:$ masses of front and rear wheel $(\mathrm{kg})$ & 14.4 \\
$k_{11}, k_{12}:$ stiffness of primary suspension system & 0.8 \\
$(\mathrm{MN} / \mathrm{m})$ & \\
$k_{t 1}, k_{t 2}:$ stiffness of Hertz contact region $(\mathrm{MN} / \mathrm{m})$ & 203.109 \\
$c_{t 1}, c_{t 2}:$ damping of Hertz contact region $(\mathrm{kNs} / \mathrm{m})$ & 16 \\
$k_{2}:$ stiffness of secondary suspension system $(\mathrm{MN} / \mathrm{m})$ & 0.4 \\
$c_{11}, c_{12}:$ damping of primary suspension system & 0.16 \\
$(\mathrm{kNs} / \mathrm{m})$ & \\
$c_{2}:$ damping of secondary suspension system & 0.64 \\
$(\mathrm{kNs} / \mathrm{m})$ &
\end{tabular}

scaled rail vehicle calculated based on the Pascal scale factor are presented in Table 2.

The 1:5 scaled roller rig has been designed so as to identify the vertical vibrational features of Y32 bogie that is also used in high-speed trains in Turkey. The drive system has been composed of a three-phase AC motor of $2 \mathrm{~kW}$ and a belt and pulley system. In the UIP60 type driven by the belt and pulley system, the rollers machined as 1:5 scaled rail profiles move the bogie wheel sets. The bogie has been modelled so as to have only the vertical components of the primary and secondary suspension systems and without a traction and bolster system. The maximum speed of the bogie in the $1: 5$ scaled roller rig can reach the speed as high as $300 \mathrm{~km} / \mathrm{h}$. To simulate the wagon mass, steel bulks of $30 \times 30 \times 30 \mathrm{~cm}$ have 


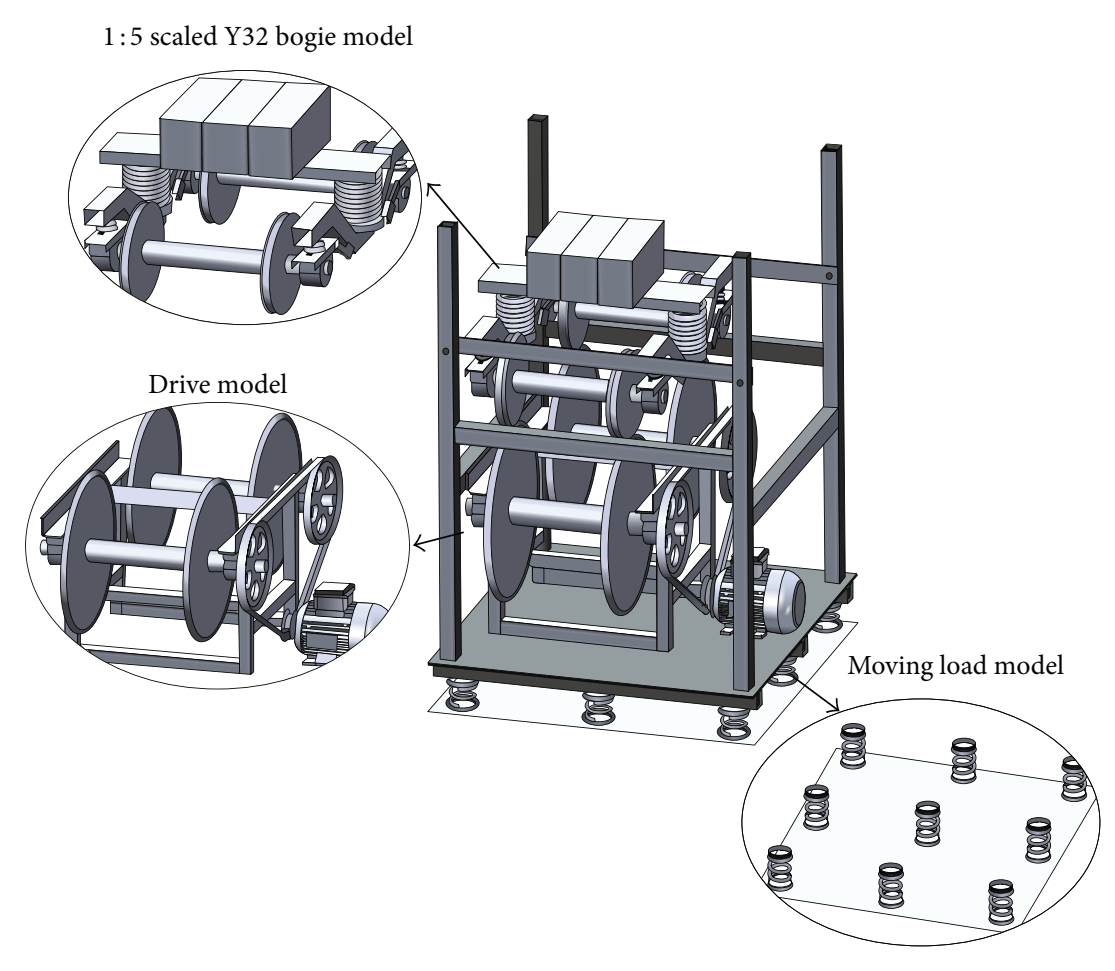

FIGURE 4: 3D CAD model of 1:5 scaled roller rig.

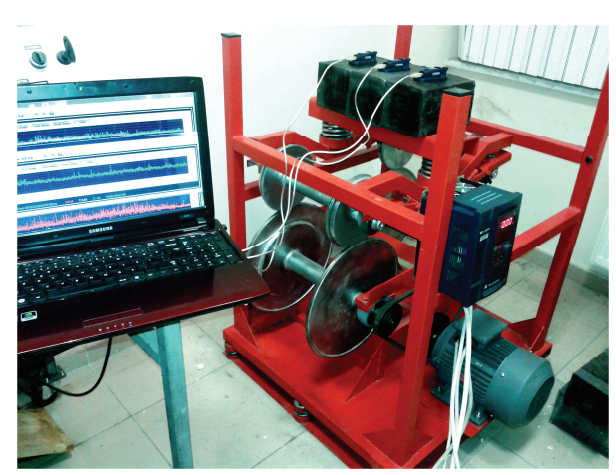

FIGURE 5: Real-time simulation of the bogie-bridge interaction on $1: 5$ scaled roller rig.

been used. A flexible structure composed of nine springs has been designed in the test stand in order to reproduce the realtime loading due to SB30 type steel bridge [34] (Figure 4).

In order to measure the vertical vibrations on the wagon masses, vibration sensors that can take measurements from 0 to $60 \mathrm{~Hz}$ frequency interval with $50 \mathrm{~ms}$ have been used (Figure 6). Data taken from the sensors have been used after filtering according to $1 \mathrm{~Hz}$ cutoff frequency at a $1 / 3$ octave band. With the help of the sensors on the wagon masses, the data taken from three different points have been averaged and the passing of the rail vehicle over the central point of the bridge has been simulated using the 1:5 roller rig (Figure 5).

\section{Validation}

For the accuracy of the dynamic model with five degrees of freedom, a series of simulations are performed in MATLAB for the rail vehicle moving over the bridge with a constant acceleration equal to $0.37 \mathrm{~m} / \mathrm{s}^{2}$ for medium and $0.49 \mathrm{~m} / \mathrm{s}^{2}$ for less comfortable passenger comfort degree with respect to ISO 2631 standard, and the simulations were executed on the $1: 5$ scaled roller rig. Three different values for the vehicle velocity $(150,200$, and $250 \mathrm{~km} / \mathrm{h})$ are used for the simulations, while the half wagon masses are chosen as 20.75 and 25.00 tons. After determining the midregion on the bridge where the vehicle passes for 1-second sampling duration, the vertical vibrations obtained from both simulations are compared, as shown in Figures 6-9.

Figures 6-9 show that the results obtained from the 1:5 scaled roller rig and the simulations are quite closer to each other, together with the increasing effect of the velocity values of the rail vehicle on the vertical vibrations. When the RMS values of the vertical vibrations obtained from the rail vehicle bridge model with 5 degrees of freedom and from the 1:5 scaled roller rig are compared to each other, it can be seen that the dynamic model and experimental methods bear the same results by a maximum error margin of $7.423 \%$ for a vehicle 


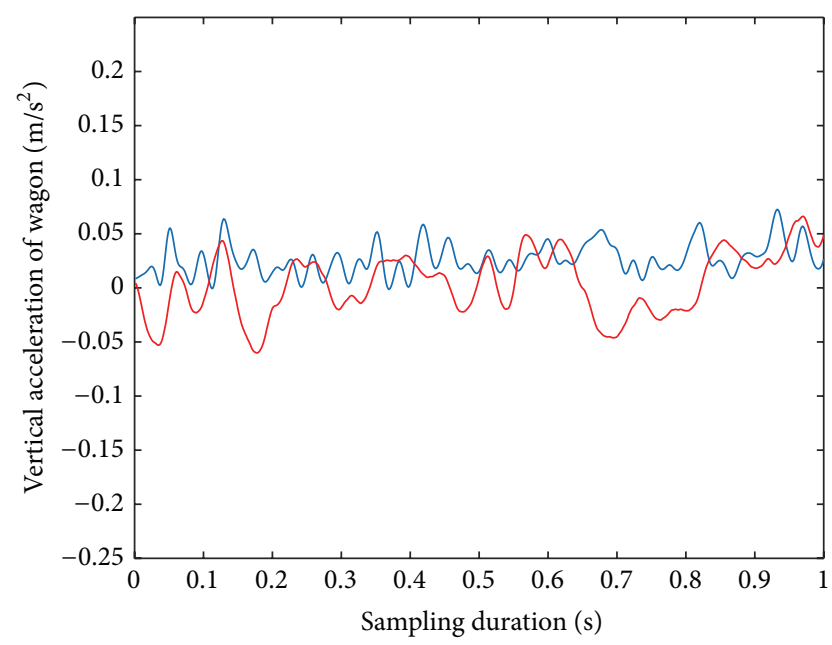

(a)

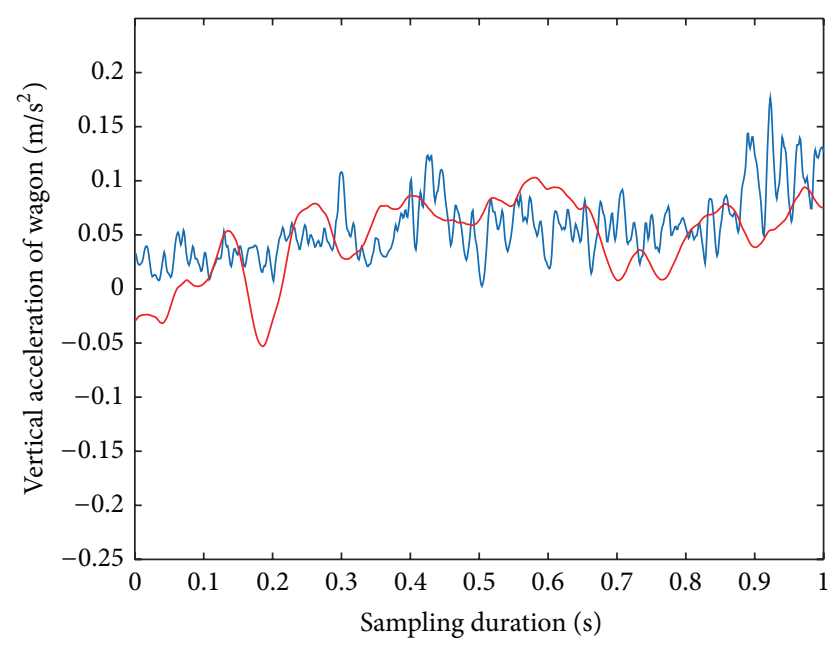

(b)

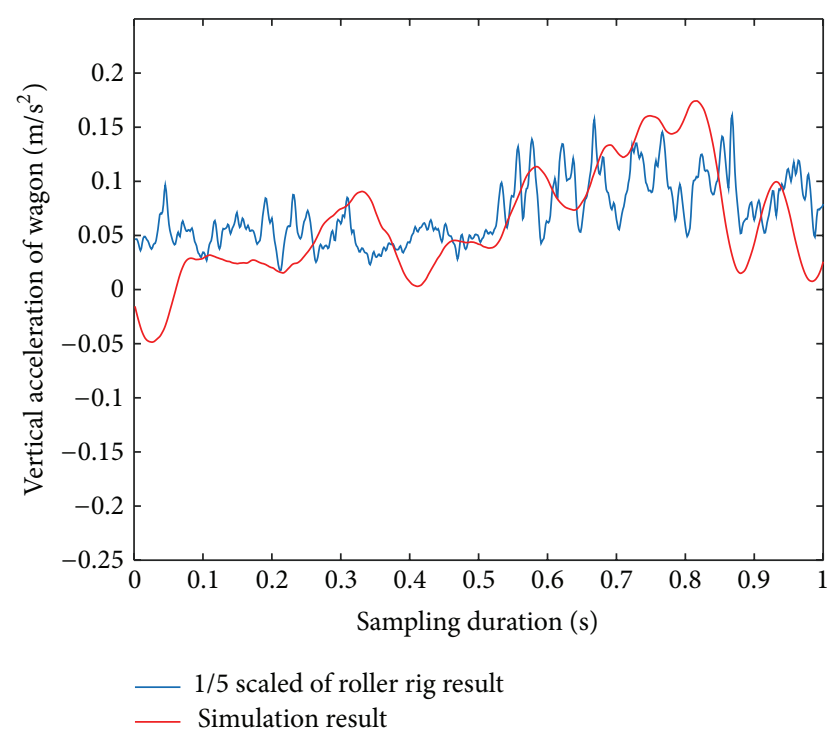

(c)

FIGURE 6: Vibration values of the rail vehicle with a half wagon of 20.75 tons moving in the horizontal plane on the bridge with an acceleration of $0.37 \mathrm{~m} / \mathrm{s}^{2}$ and with a velocity of (a) $150 \mathrm{~km} / \mathrm{h}$, (b) $200 \mathrm{~km} / \mathrm{h}$, and (c) $250 \mathrm{~km} / \mathrm{h}$.

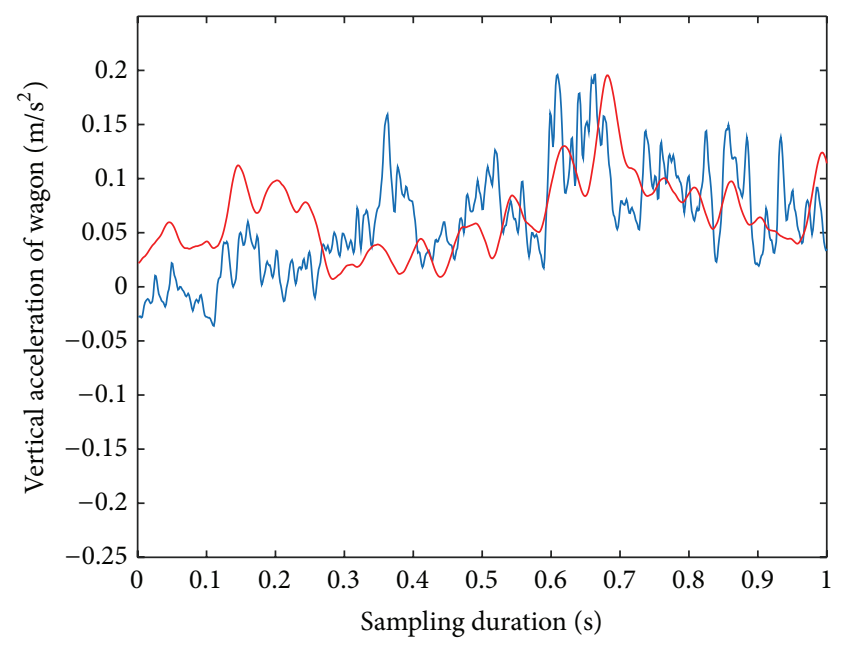

(a)

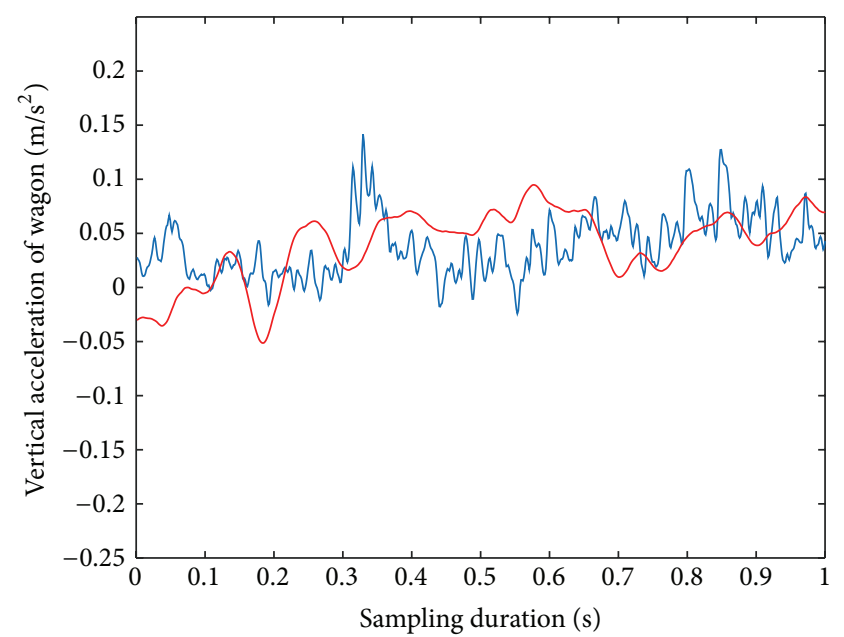

(b)

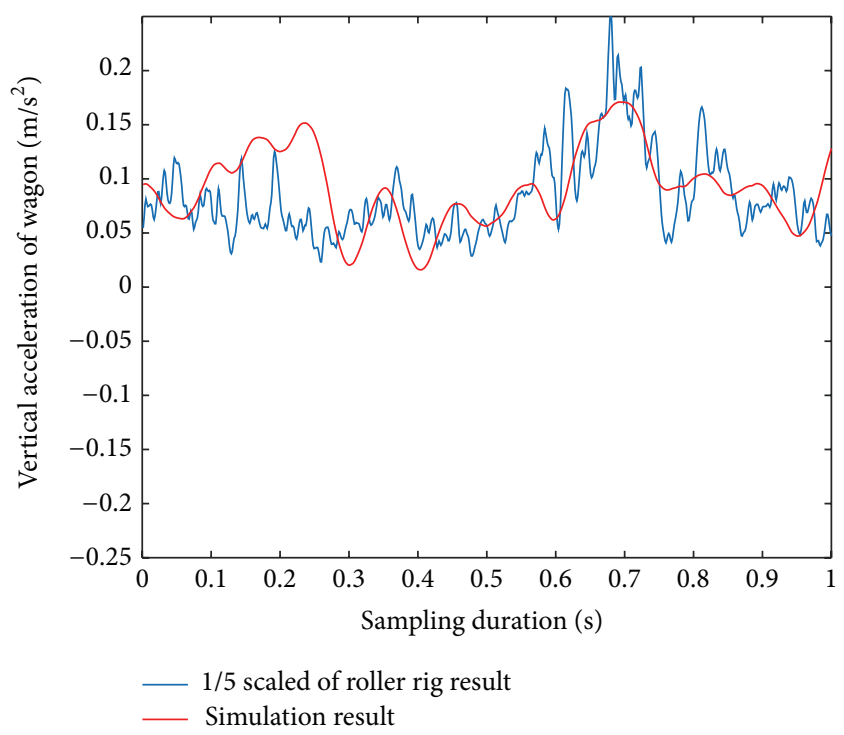

(c)

FIGURE 7: Vibration values of the rail vehicle with a half wagon of 25 tons moving in the horizontal plane on the bridge with an acceleration of $0.37 \mathrm{~m} / \mathrm{s}^{2}$ and with a velocity of (a) $150 \mathrm{~km} / \mathrm{h}$, (b) $200 \mathrm{~km} / \mathrm{h}$, and (c) $250 \mathrm{~km} / \mathrm{h}$. 


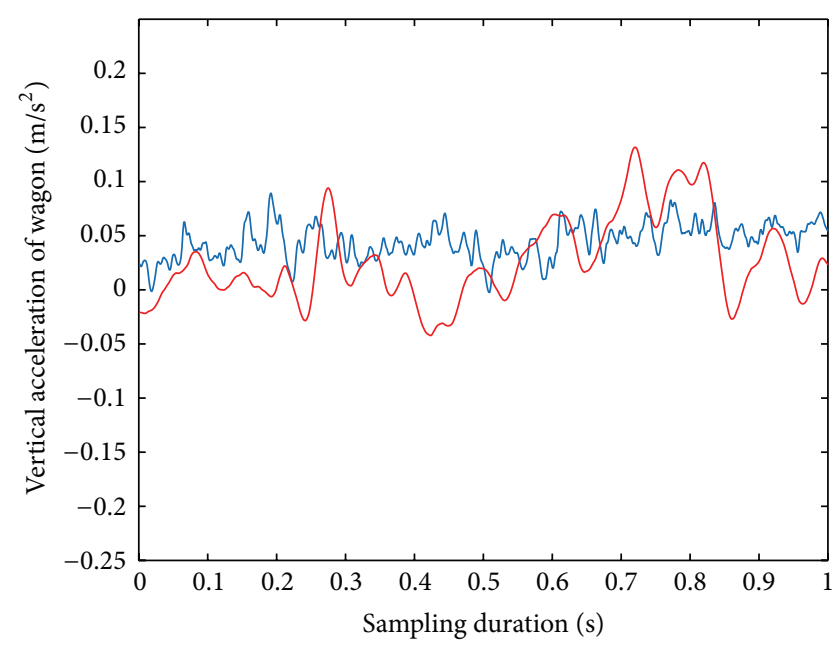

(a)

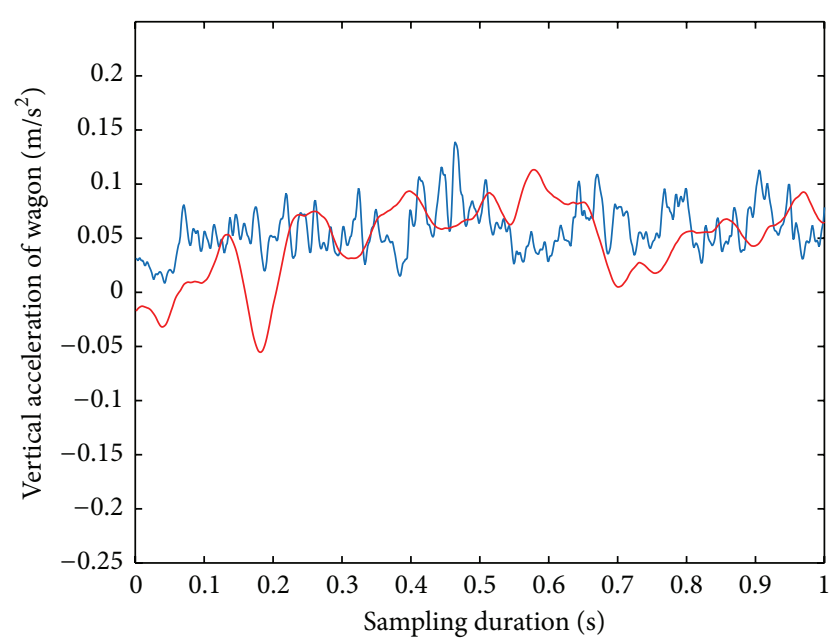

(b)

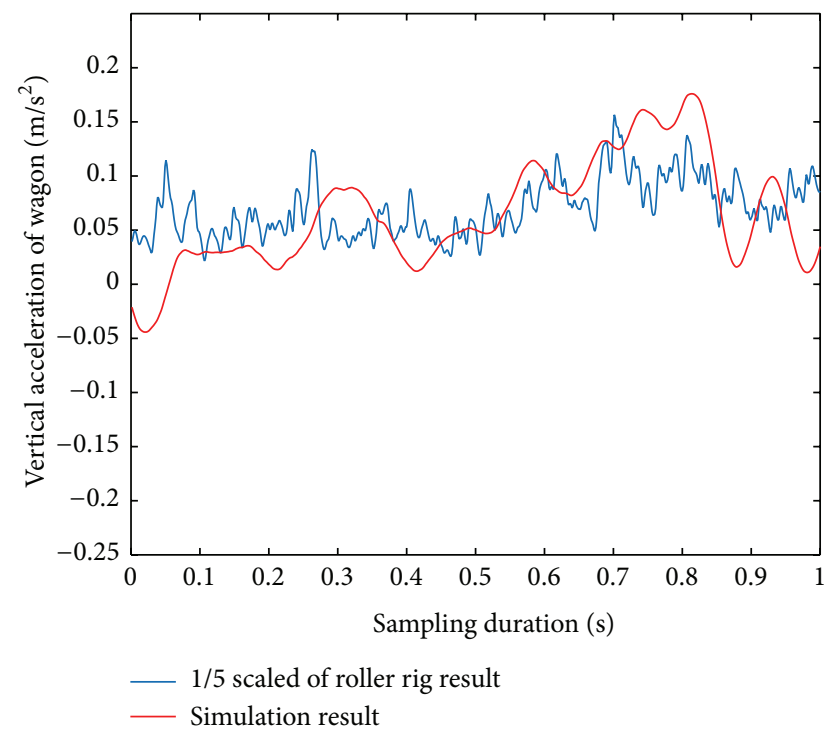

(c)

FIGURE 8: Vibration values of the rail vehicle with a half wagon of 20.75 tons moving in the horizontal plane on the bridge with an acceleration of $0.49 \mathrm{~m} / \mathrm{s}^{2}$ and with a velocity of (a) $150 \mathrm{~km} / \mathrm{h}$, (b) $200 \mathrm{~km} / \mathrm{h}$, and (c) $250 \mathrm{~km} / \mathrm{h}$.

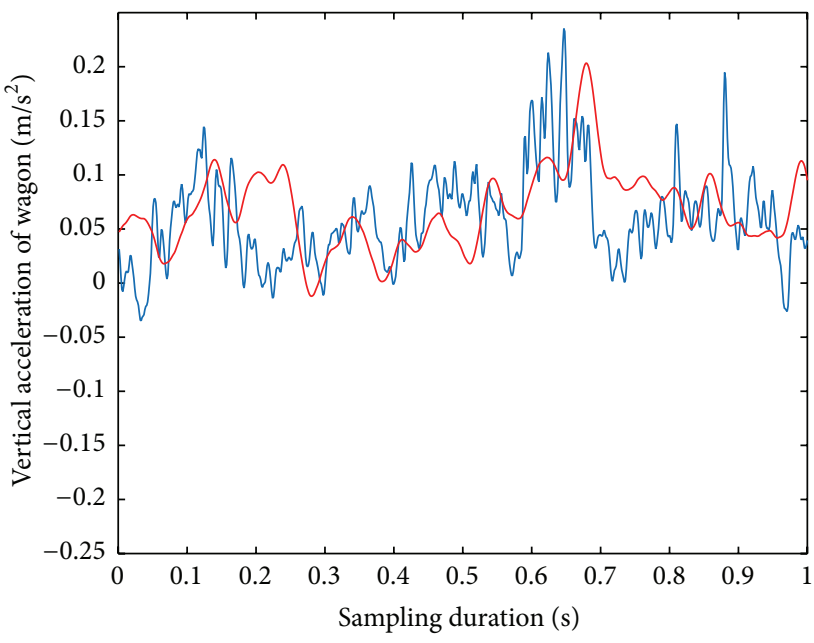

(a)

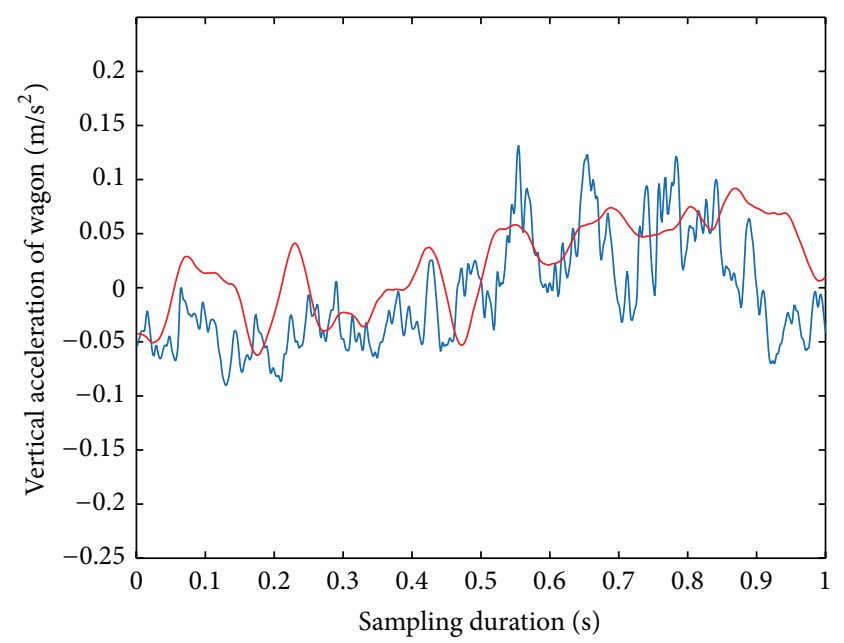

(b)

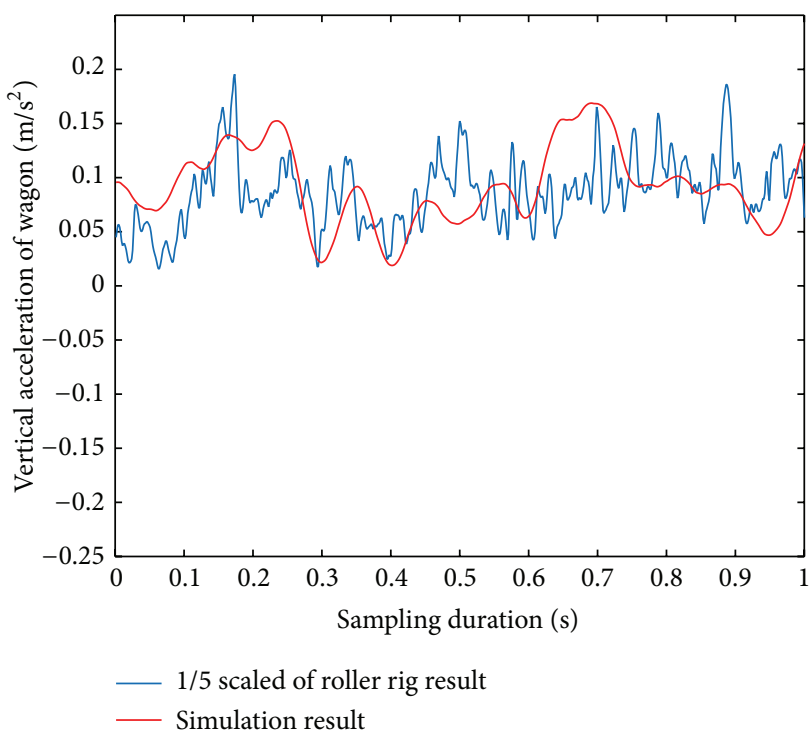

(c)

FIGURE 9: Vibration values of the rail vehicle with a half wagon of 25 tons moving in the horizontal plane on the bridge with an acceleration of $0.49 \mathrm{~m} / \mathrm{s}^{2}$ and with a velocity of (a) $150 \mathrm{~km} / \mathrm{h}$, (b) $200 \mathrm{~km} / \mathrm{h}$, and (c) $250 \mathrm{~km} / \mathrm{h}$. 


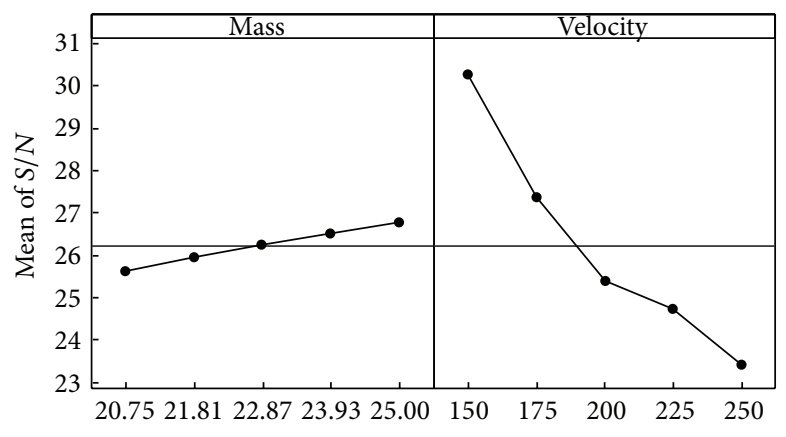

FIGURE 10: Main effects of factors.

horizontal acceleration equal to $0.37 \mathrm{~m} / \mathrm{s}^{2}$ (Table 3 ) and a maximum error margin of $8.899 \%$ for a vehicle horizontal acceleration equal to $0.49 \mathrm{~m} / \mathrm{s}^{2}$ (Table 4 ). Also it can be seen that an increase in the horizontal acceleration causes an increase in the vertical vibration at medium vehicle velocities of $150 \mathrm{~km} / \mathrm{h}$.

\section{Taguchi and ANOVA Analysis}

In this study, the Taguchi method is used as the simulation design and analysis technique. For this method, factors, levels for each factor, and data are analysed.

The standard orthogonal matrixes of the Taguchi method are used to form a simulation plan. For our system, the Taguchi L25 orthogonal matrix is selected. The wagon mass and the rail vehicle velocity are chosen as factors, and each factor has five levels. The tests designed on the basis of the Taguchi method and the RMS values of vertical vibrations obtained from numerical simulations results are given in Table 5.

The Taguchi method uses $S / N$ analysis to measure the system variance [35], where $S / N$ is the abbreviation of the ratio of the Signal and Noise. There are a number of different $S / N$ analyses on the basis of quality characteristics. These $S / N$ values are calculated and analysed in different ways based on the targeted quality value, where small values are best (SB), large values are best (LB), and nominal values are best (NB). Since the best acceleration values are the lowest ones, $\mathrm{SB} S / N$ was chosen in this study:

$$
\frac{S}{N}=-10 \log \left[\frac{1}{n} \sum_{k=1}^{n} y_{k}^{2}\right] .
$$

Here, $n$ stands for the number of measurements and $y$ stands for the characteristic value (RMS value of the vertical vibrations on the half wagon). The averages where the best acceleration values are the lowest, the ANOVAs of $S / N$ values, and main effects of individual factors are shown in Figure 10.

According to the $S / N$ ratio obtained from the Taguchi analysis, the vertical vibrations on the half wagon of the rail vehicle passing over the central point of a bridge with a constant acceleration decreased with increasing values of wagon mass. In cases where the rail vehicle velocity was between 150 and $200 \mathrm{~km} / \mathrm{h}$, the vertical vibrations of the wagon increased, while this increase continued with a decreasing rate for the rail vehicle velocity values between 200 and $250 \mathrm{~km} / \mathrm{h}$.

\section{Conclusion and Discussion}

In this study, effects of the wagon mass and vehicle velocity of a rail vehicle on the vertical vibrations of the quarter vehicle model have been determined by means of ANOVA analyses that were carried out for the averages and the $S / N$ using the method of Taguchi's design of experiment. Taguchi's design of experiment method chooses the most suitable combination of the controllable factors for the product and the process against the factors that are uncontrollable and cause variability and tries to minimize the variability for the product and the process [35].

The significance of the relevant parameter in ANOVA is determined by comparing the $F$ value, which is the ratio of the variance for that particular parameter to the error variance, to the table value of $F\left(F_{0.05}\right)$. It is specified with this method that how much the parameters determined from experimental design can explain the system. Determination of which output parameters are effected quantitatively from which input parameters supplies the required data for the optimum parameter design. Also, it can be compared that how much the input parameters are effective on the system and significance degrees of input parameters can be defined for the experiment system.

In the last column of ANOVA, the significance of each factor on the results has been given in percentages (Table 6).

The ANOVA analysis (Table 6) shows that the confidence level of the simulations is $98.47 \%$. By means of the ANOVA analysis, it has been determined that the rail vehicle velocity increases the vibrations by $96.384 \%$ and the wagon mass decreases the vertical vibrations of the rail vehicle by $2.087 \%$. Therefore, it has been proven by the experimental and numerical methods that, in the moving load-vehicle interactions, the rail velocity dominantly increases the vibrations, while an increase in mass decreases them.

In this study, the bogie-bridge interaction has been modelled by experimental and numerical methods and 
TABLE 3: Comparison of the RMS values for the experimental and numerical results for a vehicle horizontal acceleration of $0.37 \mathrm{~m} / \mathrm{s}^{2}$.

\begin{tabular}{|c|c|c|c|c|c|c|}
\hline & \multicolumn{3}{|c|}{20.75 tons } & \multicolumn{3}{|c|}{25.0 tons } \\
\hline & $150 \mathrm{~km} / \mathrm{h}$ & $200 \mathrm{~km} / \mathrm{h}$ & $250 \mathrm{~km} / \mathrm{h}$ & $150 \mathrm{~km} / \mathrm{h}$ & $200 \mathrm{~km} / \mathrm{h}$ & $250 \mathrm{~km} / \mathrm{h}$ \\
\hline $1: 5$ scaled roller rig (RMS) & 0.030 & 0.065 & 0.076 & 0.078 & 0.048 & 0.093 \\
\hline Numerical method (RMS) & 0.029 & 0.060 & 0.080 & 0.075 & 0.052 & 0.099 \\
\hline Error \% & 3.974 & 7.109 & 4.8314 & 3.814 & 7.423 & 6.685 \\
\hline
\end{tabular}

TABLE 4: Comparison of the RMS values for the experimental and numerical results for a vehicle horizontal acceleration of $0.49 \mathrm{~m} / \mathrm{s}^{2}$.

\begin{tabular}{|c|c|c|c|c|c|c|}
\hline & \multicolumn{3}{|c|}{20.75 tons } & \multicolumn{3}{|c|}{25.0 tons } \\
\hline & $150 \mathrm{~km} / \mathrm{h}$ & $200 \mathrm{~km} / \mathrm{h}$ & $250 \mathrm{~km} / \mathrm{h}$ & $150 \mathrm{~km} / \mathrm{h}$ & $200 \mathrm{~km} / \mathrm{h}$ & $250 \mathrm{~km} / \mathrm{h}$ \\
\hline $1: 5$ scaled roller rig (RMS) & 0.044 & 0.062 & 0.075 & 0.078 & 0.046 & 0.093 \\
\hline Numerical method (RMS) & 0.048 & 0.061 & 0.082 & 0.075 & 0.050 & 0.099 \\
\hline Error \% & 7.713 & 2.649 & 8.899 & 3.814 & 8.922 & 6.685 \\
\hline
\end{tabular}

TABLE 5: DOE of Taguchi and result of numerical simulations.

\begin{tabular}{|c|c|c|}
\hline Mass (ton) & Velocity $(\mathrm{km} / \mathrm{h})$ & $\begin{array}{l}\text { RMS value of vertical } \\
\text { vibrations }\end{array}$ \\
\hline 20.75 & 150 & 0.0351351 \\
\hline 20.75 & 175 & 0.0479867 \\
\hline 20.75 & 200 & 0.0580008 \\
\hline 20.75 & 225 & 0.0597233 \\
\hline 20.75 & 250 & 0.0664698 \\
\hline 21.81 & 150 & 0.0327729 \\
\hline 21.81 & 175 & 0.0452646 \\
\hline 21.81 & 200 & 0.0556734 \\
\hline 21.81 & 225 & 0.0586297 \\
\hline 21.81 & 250 & 0.0668451 \\
\hline 22.87 & 150 & 0.0306099 \\
\hline 22.87 & 175 & 0.0427376 \\
\hline 22.87 & 200 & 0.0535974 \\
\hline 22.87 & 225 & 0.0578077 \\
\hline 22.87 & 250 & 0.0674095 \\
\hline 23.93 & 150 & 0.0286403 \\
\hline 23.93 & 175 & 0.040397 \\
\hline 23.93 & 200 & 0.0517565 \\
\hline 23.93 & 225 & 0.057224 \\
\hline 23.93 & 250 & 0.0681211 \\
\hline 25.00 & 150 & 0.0268451 \\
\hline 25.00 & 175 & 0.0382161 \\
\hline 25.00 & 200 & 0.0501209 \\
\hline 25.00 & 225 & 0.0568453 \\
\hline 25.00 & 250 & 0.0689533 \\
\hline
\end{tabular}

a series of real-time simulations were performed. In the 1:5 scaled roller rig, only vertical vibrations can be determined; however, future studies will concentrate on integrating lateral vibrations and different road roughness types into the roller rig and their effects on passenger comfort and driving safety will be determined with real-time simulations.

\section{Appendices}

\section{A. The Mass, Damping, Stiffness Matrices, and Force and Displacement Vectors of the Quarter Vehicle}

Matrixes of general mass $\left(M_{s v}\right)$, general damping $\left(C_{s v}\right)$, and general stiffness $\left(K_{s v}\right)$ and vectors of general displacement $\left(Z_{s v}\right)$ and general force $\left(Q_{s v}\right)$ for the quarter vehicle are

$$
\begin{aligned}
M_{s v} & =\left[\begin{array}{ccccc}
m_{v} & 0 & 0 & 0 & 0 \\
0 & m_{b j} & 0 & 0 & 0 \\
0 & 0 & J_{b j} & 0 & 0 \\
0 & 0 & 0 & m_{t 1} & 0 \\
0 & 0 & 0 & 0 & m_{t 2}
\end{array}\right], \\
C_{s v} & =\left[\begin{array}{ccccc}
c_{2} & -c_{2} & 0 & 0 & 0 \\
-c_{2} & c_{2}+c_{11}+c_{12} & c_{11} l_{a}-c_{12} l_{b} & -c_{11} & -c_{12} \\
0 & c_{11} l_{a}-c_{12} l_{b} & c_{11} l_{a}^{2}+c_{12} l_{b}^{2} & -c_{11} l_{a} & c_{12} l_{b} \\
0 & -c_{11} & -c_{11} l_{a} & c_{11}+c_{t 1} & 0 \\
0 & -c_{12} & c_{12} l_{b} & 0 & c_{12}+c_{t 2}
\end{array}\right],
\end{aligned}
$$

$K_{s v}$

$$
=\left[\begin{array}{ccccc}
k_{2} & -k_{2} & 0 & 0 & 0 \\
-k_{2} & k_{2}+k_{11}+k_{12} & k_{11} l_{a}-k_{12} l_{b} & -k_{11} & -k_{12} \\
0 & k_{11} l_{a}-k_{12} l_{b} & k_{11} l_{a}^{2}+k_{12} l_{b}^{2} & -k_{11} l_{a} & k_{12} l_{b} \\
0 & -k_{11} & -k_{11} l_{a} & k_{11}+k_{t 1} & 0 \\
0 & -k_{12} & k_{12} l_{b} & 0 & k_{12}+k_{t 2}
\end{array}\right],
$$

$Z_{s v}=\left[\begin{array}{c}z_{v} \\ z_{b j} \\ \theta \\ z_{t 1} \\ z_{t 2}\end{array}\right]$

$Q_{s v}=\left[\begin{array}{c}0 \\ 0 \\ 0 \\ k_{t 1} z_{c 1}+c_{t 1} \dot{z}_{c 1} \\ k_{t 2} z_{c 2}+c_{t 2} \dot{z}_{c 2}\end{array}\right]$ 
TABLE 6: Results of ANOVA.

\begin{tabular}{|c|c|c|c|c|c|c|}
\hline Source & Degree of freedom (DF) & Sum of squares (SS) & Mean of squares (MS) & $F$ ratio & $P$ value & PCR (\%) \\
\hline Wagon mass & 4 & 0.0000871 & 0.0000218 & 5.45 & 0.006 & 2.087027364 \\
\hline Velocity & 4 & 0.0040225 & 0.0010056 & 251.92 & 0 & 96.38424306 \\
\hline Error & 16 & 0.0000639 & 0.000004 & & & 1.531125701 \\
\hline Total & 24 & 0.0041734 & & & & 100 \\
\hline
\end{tabular}

\section{B. The General Mass, Damping, Stiffness Matrices, and Force and Displacement Vectors of the Vehicle-Brdige Interaction}

Matrixes of general mass $\left(M_{c}\right)$, general damping $\left(C_{c}\right)$, and general stiffness $\left(K_{c}\right)$ and vectors of general displacement
$\left(Z_{c}\right)$ and general force $\left(Q_{c}\right)$ for coupled of the vehicle bridge interaction are

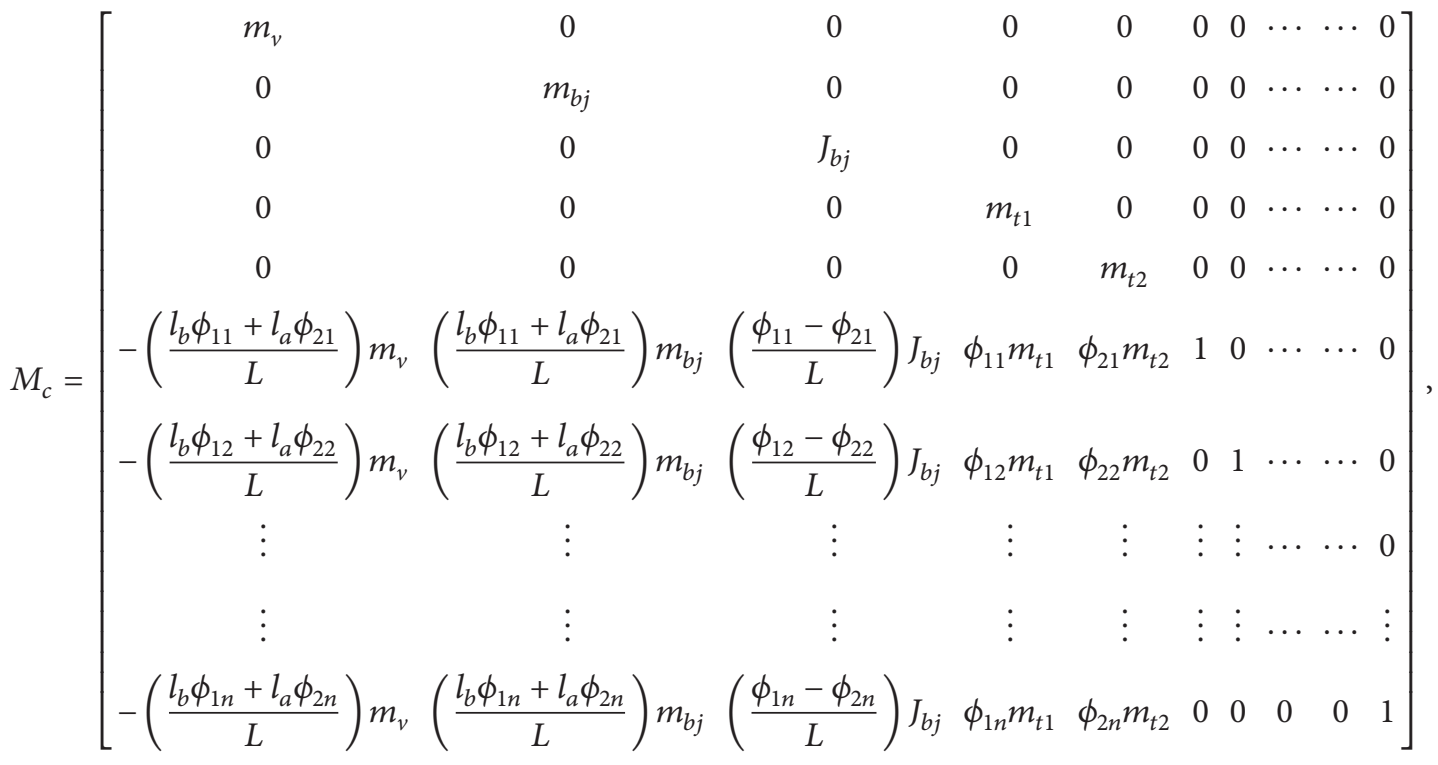

$$
\begin{aligned}
& C_{c}=\left[\begin{array}{cccccccccc}
c_{2} & -c_{2} & 0 & 0 & 0 & 0 & 0 & \cdots & \ldots & 0 \\
-c_{2} & c_{2}+c_{11}+c_{12} & c_{11} l_{a}-c_{12} l_{b} & -c_{11} & -c_{12} & 0 & 0 & \ldots & \ldots & 0 \\
0 & c_{11} l_{a}-c_{12} l_{b} & c_{11} l_{a}^{2}+c_{12} l_{b}^{2} & -c_{11} l_{a} & c_{12} l_{b} & 0 & 0 & \ldots & \ldots & 0 \\
0 & -c_{11} & -c_{11} l_{a} & c_{11}+c_{t 1} & 0 & -c_{t 1} \dot{\phi}_{11} & -c_{t 1} \dot{\phi}_{12} & \ldots & \ldots & -c_{t 1} \dot{\phi}_{1 n} \\
0 & -c_{12} & c_{12} l_{b} & 0 & c_{12}+c_{t 2} & -c_{t 2} \dot{\phi}_{21} & -c_{t 2} \dot{\phi}_{22} & \ldots & \ldots & -c_{t 2} \dot{\phi}_{2 n} \\
0 & 0 & 0 & 0 & 0 & 2 \zeta_{1} \omega_{1} & & \ldots & \ldots & 0 \\
0 & 0 & 0 & 0 & 0 & 0 & 2 \zeta_{2} \omega_{2} & \ldots & \ldots & 0 \\
\vdots & \vdots & \vdots & \vdots & \vdots & \vdots & \vdots & \ldots & \ldots & \vdots \\
\vdots & \vdots & \vdots & \vdots & \vdots & \vdots & \vdots & \ldots & \ldots & \vdots \\
0 & 0 & 0 & 0 & 0 & 0 & 0 & 0 & 0 & 2 \zeta_{n} \omega_{n}
\end{array}\right],
\end{aligned}
$$




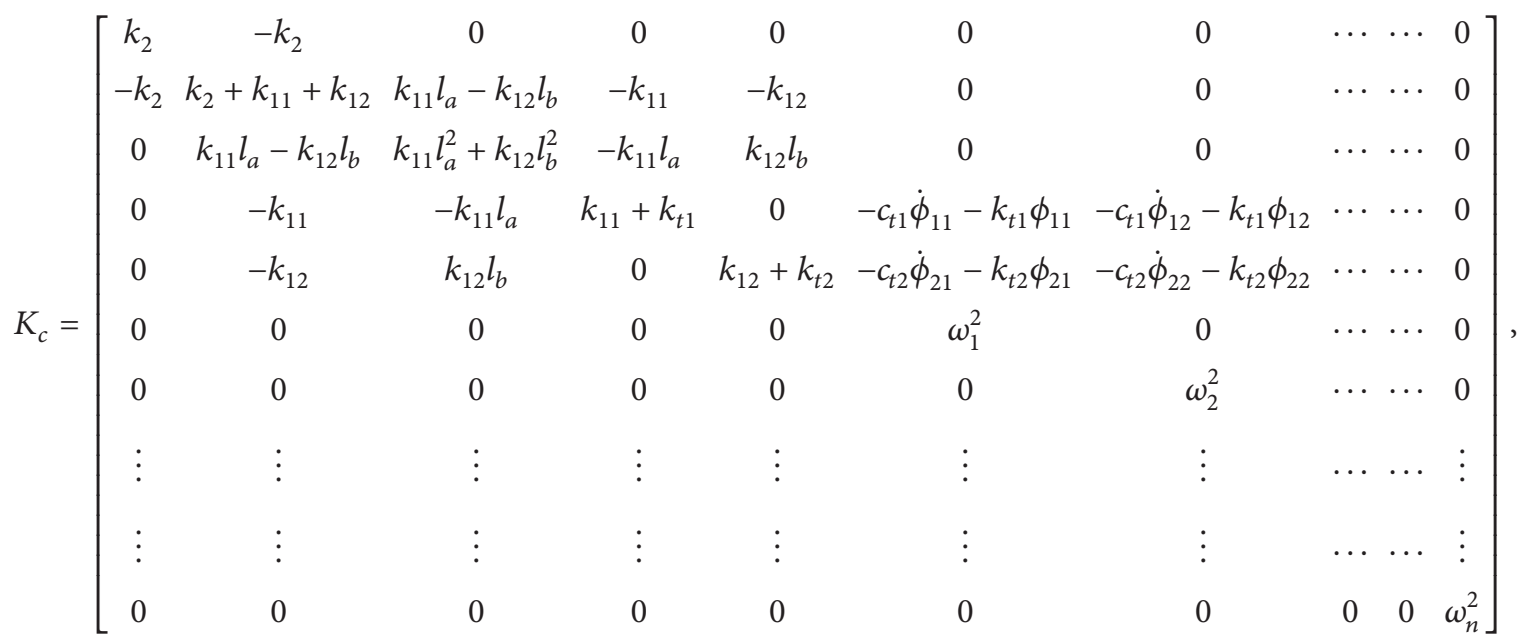

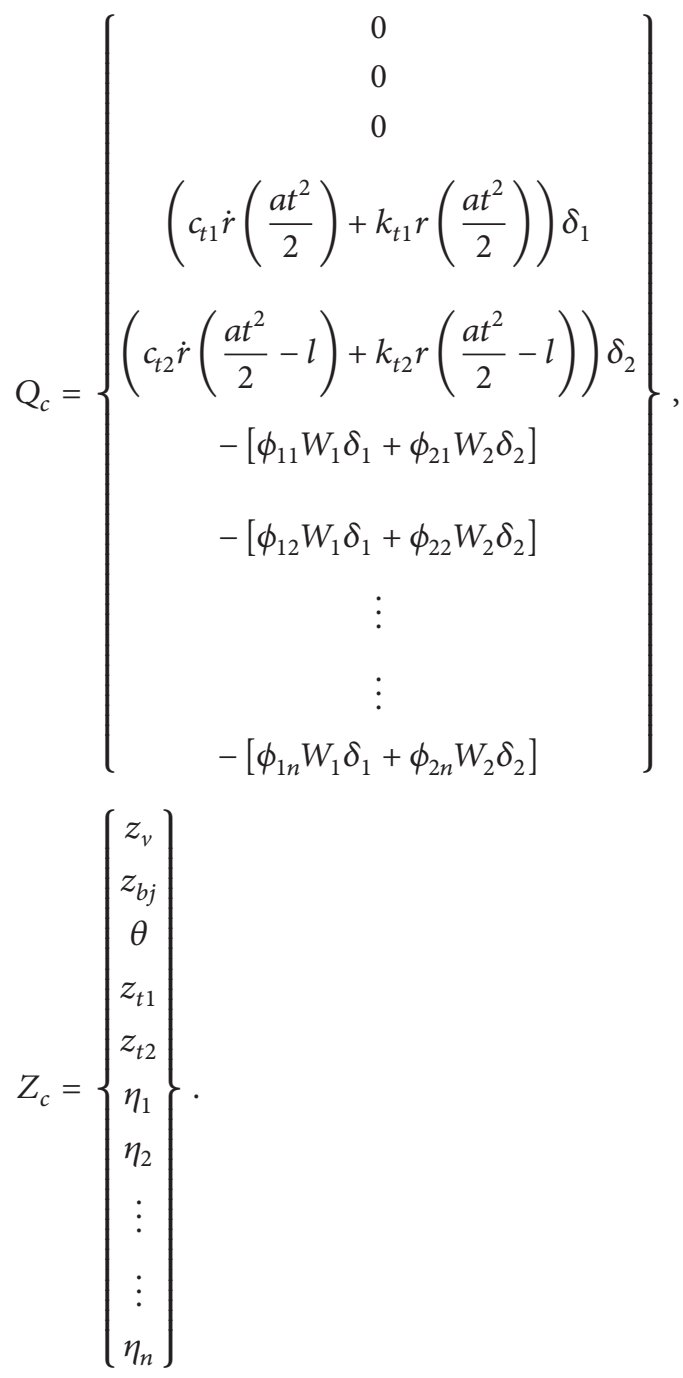

\section{Conflict of Interests}

The authors declare that there is no conflict of interests regarding the publication of this paper.

\section{Acknowledgments}

This study was conducted within the scope of the (TÜBİTAKKAMAG-112G012) project. The authors would like to express 
their thanks and gratitude to TÜBİTAK (Scientific and Technological Research Council of Turkey) for its financial support.

\section{References}

[1] J. M. Biggs, Introduction to Structural Dynamics, McGraw-Hill, New York, NY, USA, 1964.

[2] E. Esmailzadeh and N. Jalili, "Vehicle-passenger-structure interaction of uniform bridges traversed by moving vehicles," Journal of Sound and Vibration, vol. 260, no. 4, pp. 611-635, 2003.

[3] L. Fryba, Vibration of Solids and Structures under Moving Loads, Thomas Telford, London, UK, 1999.

[4] T. Matsudaira, N. Matsui, S. Arai, and K. Jokose, "Problems on hunting of railway vehicle on test stand," Journal of Manufacturing Science and Engineering Series B, vol. 91, no. 3, pp. 879-885, 1969.

[5] L. M. Sweet, A. Karmel, and S. R. Fairley, "Derailment mechanics and safety criteria for complete railway vehicle trucks," Vehicle System Dynamics, vol. 10, no. 2-3, pp. 203-206, 1982.

[6] N. Zhang, H. Xia, and G. de Roeck, "Dynamic analysis of a train-bridge system under multi-support seismic excitations," Journal of Mechanical Science and Technology, vol. 24, no. 11, pp. 2181-2188, 2010.

[7] J. J. Wu, A. R. Whittaker, and M. P. Cartmell, "Dynamic responses of structures to moving bodies using combined finite element and analytical methods," International Journal of Mechanical Sciences, vol. 43, no. 11, pp. 2555-2579, 2001.

[8] H. Xia, G. De Roeck, N. Zhang, and J. Maeck, "Experimental analysis of a high-speed railway bridge under Thalys trains," Journal of Sound and Vibration, vol. 268, no. 1, pp. 103-113, 2003.

[9] H. Azimi, K. Galal, and O. A. Pekau, "A modified numerical VBI element for vehicles with constant velocity including road irregularities," Engineering Structures, vol. 33, no. 7, pp. 22122220, 2011.

[10] P. Lou, "Vertical dynamic responses of a simply supported bridge subjected to a moving train with two-wheelset vehicles using modal analysis method," International Journal for Numerical Methods in Engineering, vol. 64, no. 9, pp. 1207-1235, 2005.

[11] R. D. Machado and V. Bernardes, "Dynamic analysis of vehiclebridge interaction," in Proceedings of the 19th International Congress of Mechanical Engineering, Brasília, Brazil, 2007.

[12] X.-W. Liu, J. Xie, C. Wu, and X.-C. Huang, "Semi-analytical solution of vehicle-bridge interaction on transient jump of wheel," Engineering Structures, vol. 30, no. 9, pp. 2401-2412, 2008.

[13] K. Youcef, T. Sabiha, D. El Mostafa, D. Ali, and M. Bachir, "Dynamic analysis of train-bridge system and riding comfort of trains with rail irregularities," Journal of Mechanical Science and Technology, vol. 27, no. 4, pp. 951-962, 2013.

[14] M. Majka and M. Hartnett, "Effects of speed, load and damping on the dynamic response of railway bridges and vehicles," Computers and Structures, vol. 86, no. 6, pp. 556-572, 2008.

[15] D. M. Yoshida and W. Weaver, "Finite element analysis of beams and plates with moving loads," Publications for International Association for Bridge and Structural Engineering, vol. 31, no. 1, pp. 79-195, 1971.

[16] İ. Esen, "A new FEM procedure for transverse and longitudinal vibration analysis of thin rectangular plates subjected to a variable velocity moving load along an arbitrary trajectory,"
Latin American Journal of Solids and Structures, vol. 12, pp. 808830, 2015.

[17] M. H. Kargarnovin, D. Younesian, D. Thompson, and C. Jones, "Ride comfort of high-speed trains travelling over railway bridges," Vehicle System Dynamics, vol. 43, no. 3, pp. 173-199, 2005.

[18] F. W. Carter, "On the action of a locomotive driving wheel," Proceedings of the Royal Society of London, vol. 112, no. 760, pp. 151-157, 1926.

[19] J.-S. Wu and L.-K. Chiang, "Out-of-plane responses of a circular curved Timoshenko beam due to a moving load," International Journal of Solids and Structures, vol. 40, no. 26, pp. 7425-7448, 2003.

[20] C.-J. Huang, J.-S. Lin, and C.-C. Chen, "Road-adaptive algorithm design of half-car active suspension system," Expert Systems with Applications, vol. 37, no. 6, pp. 4392-4402, 2010.

[21] R.-T. Wang, "Vibration of multi-span Timoshenko beams to a moving force," Journal of Sound and Vibration, vol. 207, no. 5, pp. 731-742, 1997.

[22] S. D. Iwnicki, W. Zhang, and J. Lin, "Study on a 1/5 scale railway roller rig," Chinese Journal of Mechanical Engineering, vol. 34, no. 4,1998 .

[23] A. Jaschinski, H. Chollet, S. Iwnicki, A. Wickens, and J. V. Würzen, "The application of roller rigs to railway vehicle dynamics," Vehicle System Dynamics, vol. 31, no. 5-6, pp. 345392, 1999.

[24] M. Cox and H. Nicolin, "Untersuchung des Schwingungsverhaltens von Schienenfahrzeugen mit Hilfe des Modellprü fstands am Institut für Fördertechnik und Schienenfahrzeuge der RWTH Aachen," Leichtbau der Verkehrsfahrzeuge, vol. 23, no. 4, pp. 91-95, 1979.

[25] H. Chollet, Etude en similitude mécanique du contact roue raie [Ph.D. thesis], Université de Paris, Paris, France, 1991.

[26] N. Bosso, A. Gugliotta, and A. Somà, "Simulation of narrow gauge railway vehicles and experimental validation by mean of scaled tests on roller rig," Meccanica, vol. 43, no. 2, pp. 211-223, 2008.

[27] N. Bosso, A. Gugliotta, A. Somà, and M. Spiryagin, "Adhesion force estimation on 1/5 test rig," in Proceedings of the Multibody Dynamics: Computational Methods and Applications Eccomas Thematic Conference, pp. 1-19, Warsaw, Poland, 2009.

[28] N. Bosso, A. Gugliotta, A. Somà, and M. Spiryagin, "Methodology for the determination of wheel-roller friction coefficient on 1/5 scaled test rig," in Proceedings of the 8th International Conference on Contact Mechanics and Wear of Rail/Wheel systems (CM '09), pp. 1-6, Firenze, Italy, September 2009.

[29] İ. Esen, "A new finite element for transverse vibration of rectangular thin plates under a moving mass," Finite Elements in Analysis and Design, vol. 66, pp. 26-35, 2013.

[30] N. Bosso, A. Gugliotta, E. Napolii, and A. Somà, "Simulation of a scaled roller rig," in Proceedings of the 5th ADAMS/Rail Users Conference, pp. 1-10, Torino, Italy, 2000.

[31] CEN-European Committee for Standardization, "Railway applications-ride comfort for passengers-measurement and evaluation," EN 12299, CEN-European Committee for Standardization, 2009.

[32] G. Kouroussis, O. Verlinden, and C. Conti, "Contribution of vehicle/track dynamics to the ground vibrations induced by the Brussels tramway," in Proceedings of the ISMA 2010 International Conference on Noise and Vibration Engineering, pp. 3489-3502, Leuven, Belgium, 2010. 
[33] V. K. Garg and R. V. Dukkipati, Dynamics of Railway Vehicle Systems, Academic Press, Toronto, Canada, 1984.

[34] M. Klasztorny, K. Myslecki, C. Machelski, and M. Podworna, "Dynamic analysis of a series-of-types of steel beam bridges loaded by a Shinkansen train moving at high speeds," in Proceedings of the 4th International Conference on Structural Dynamics, pp. 1779-1184, Munich, Germany, September 2002.

[35] C. Göloğlu and C. Mizrak, "Customer driven product determination with fuzzy logic and Taguchi approaches," Journal of the Faculty of Engineering and Architecture of Gazi University, vol. 25, no. 1, pp. 9-19, 2010. 

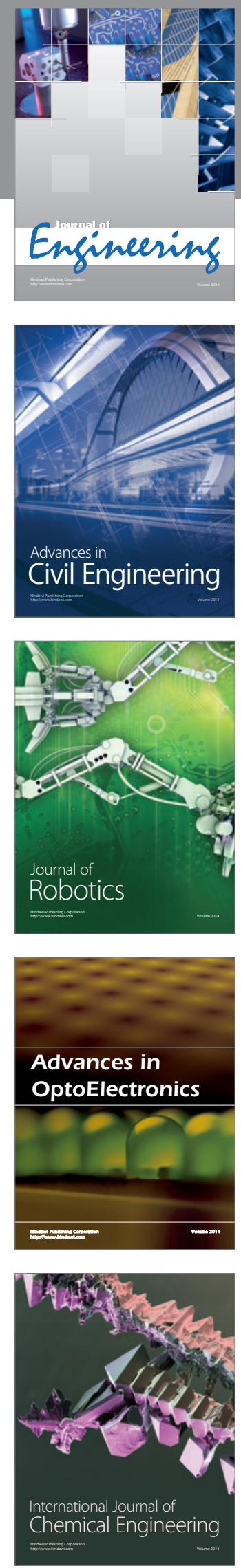

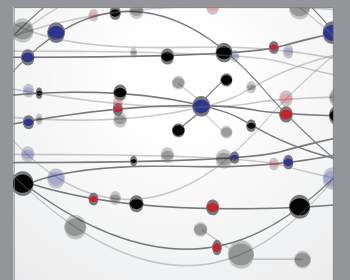

The Scientific World Journal
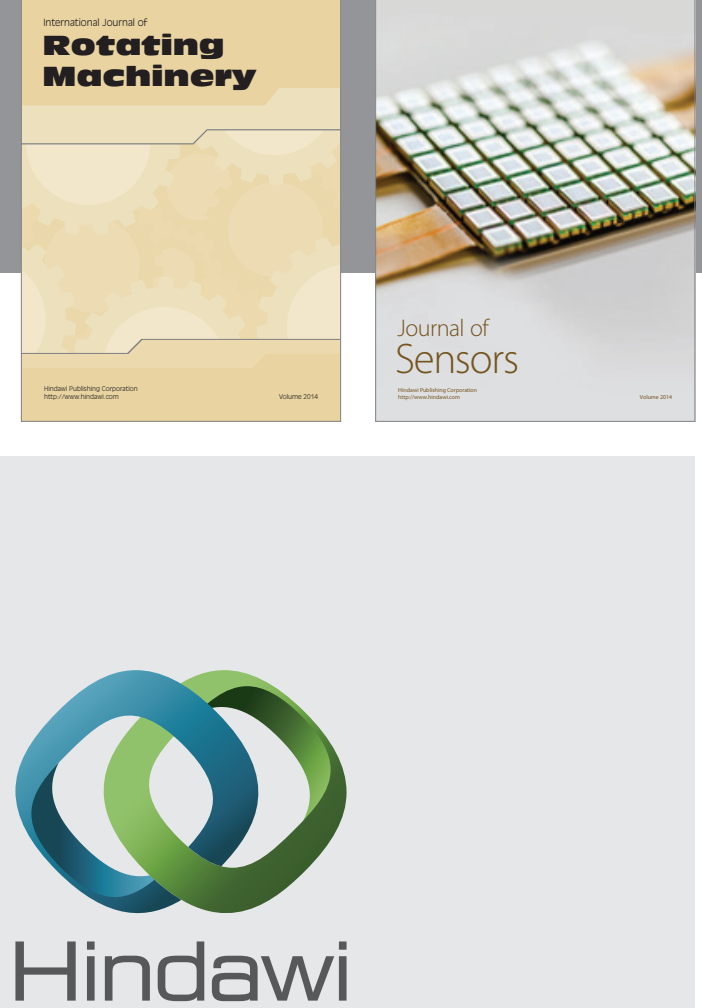

Submit your manuscripts at http://www.hindawi.com
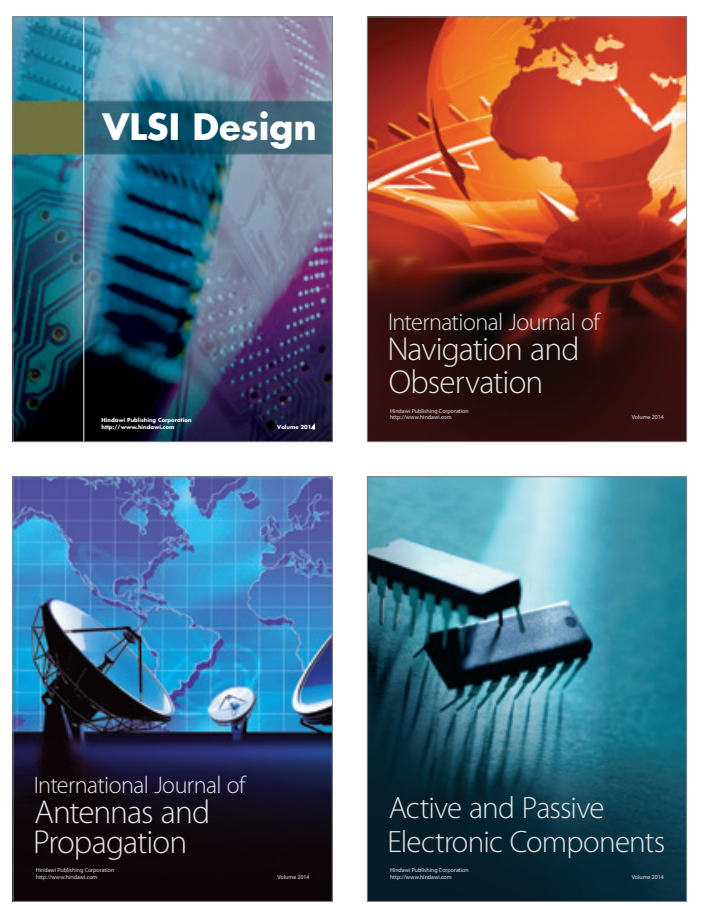
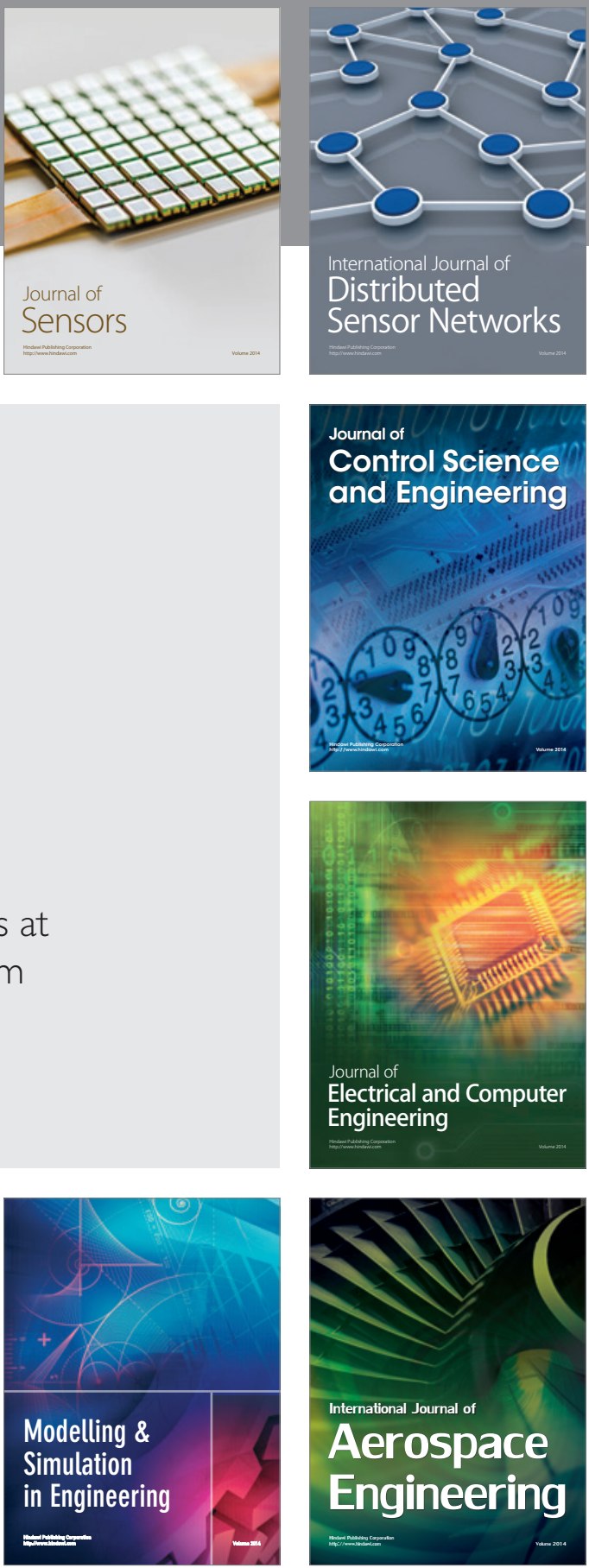

Journal of

Control Science

and Engineering
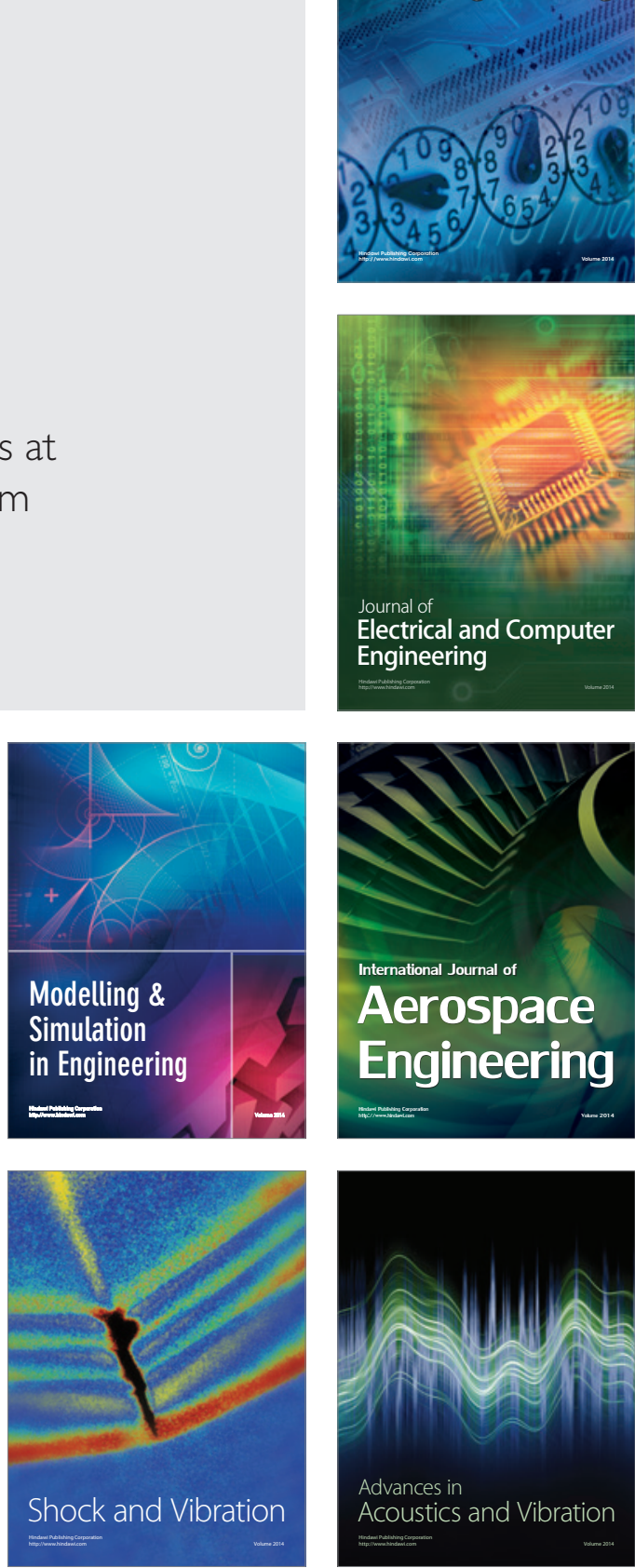